\title{
Statistical Analysis of Lightning Flashes over Wind Parks in Greece
}

\author{
Vasilios P. Androvitsaneas (D, Katerina D. Damianaki, Eleni P. Nicolopoulou and Ioannis F. Gonos * \\ High Voltage and Electrical Measurements Laboratory, School of Electrical and Computer Engineering, National \\ Technical University of Athens, 15780 Athens, Greece; v.andro@mail.ntua.gr (V.P.A.); \\ katiadamianaky@msn.com (K.D.D.); hveleni@mail.ntua.gr (E.P.N.) \\ * Correspondence: igonos@cs.ntua.gr; Tel.: +30-210-772-3539
}

Citation: Androvitsaneas, V.P.;

Damianaki, K.D.; Nicolopoulou, E.P.; Gonos, I.F. Statistical Analysis of Lightning Flashes over Wind Parks in Greece. Energies 2021, 14, 6076. https://doi.org/10.3390/en14196076

Academic Editor: Mario Marchesoni

Received: 16 July 2021

Accepted: 15 September 2021

Published: 24 September 2021

Publisher's Note: MDPI stays neutral with regard to jurisdictional claims in published maps and institutional affiliations.

Copyright: (c) 2021 by the authors. Licensee MDPI, Basel, Switzerland. This article is an open access article distributed under the terms and conditions of the Creative Commons Attribution (CC BY) license (https:// creativecommons.org/licenses/by/ $4.0 /)$.

\begin{abstract}
Currently, lightning phenomenon, mechanisms, and impacts on lives and infrastructures have been satisfactorily decoded and studied. Sound knowledge of lightning parameters is available in international literature. Yet, there are few studies referring to lightning statistics such as the number of flashes over an area, current amplitude distribution, etc., except for official documentation from national weather services, perhaps because of the stochastic nature of lightning. This work presents full recorded data for lightning flashes over wind farms distributed at the Hellenic territory. The data come from real time measurements at wind farm stations from 2011 to 2020 and concern number of CG flashes and lightning current amplitude. They are statistically processed and analyzed and contain useful information regarding the lightning characteristics of various geographic regions all over the country. Furthermore, the study displays data from field measurements of ground resistance at wind turbines and highlights techniques of designing and enhancing grounding systems of wind turbines for given lightning protection level (LPL). The present study, therefore, provides stakeholders with useful data and noteworthy conclusions about lightning occurrence and characteristics in Greece in order to make informed decisions on the various project stages, such as selection of the wind farm site, proper and in-depth risk assessment, and investment in safety measures for personnel and equipment.
\end{abstract}

Keywords: lightning; lightning current; probability distribution; wind turbine generators; earthing system; ground resistance

\section{Introduction}

Lightning is one of the most awesome, severe, and destructive natural atmospheric phenomena causing horror and astonishment to humans. People of antiquity had reasonable grounds to believe in a divine origin of lightning, because of its dazzling glow coming from the heaven down to earth, followed by an enormous bang and devastating results such as deaths, injuries, forest fires, and serious damages to properties. Ancient Greeks, for example, believed that lightning was one of Zeus' weapons that used to punish humans and other divine entities. Those mythical beliefs lasted for several centuries, keeping people away from the unknown and mysterious nature of this phenomenon, until Benjamin Franklin revealed the physics and the electric nature of lightning in the middle of 18th century.

Hundreds of years have passed since that great discovery and a lot of things are now clear and well known for the conditions and mechanisms triggering the lightning occurrence. Significant research work has been done on investigating the natural mechanisms of the phenomenon and the ways people may protect their lives and properties from dreadful consequences following a lightning stroke. Lightning phenomenon operates exactly as a charged capacitor, i.e., the leader or the cloud lower surface is considered as the charged surface and all the conductive surfaces on the earth as uncharged. Lightning may be determined as a transient, high-current electric discharge in air of tens or even few 
hundreds of kiloamperes, extended in dozens of kilometers. The entire phenomenon of this lightning discharge including the total mechanisms and the single processes is generally termed as "lightning flash". The lightning flash that particularly involves structures or objects on the ground, or the ground itself, is sometimes called a "lightning strike". The global lightning flash activity is estimated from a few tens to nearly a hundred flashes per second, about three quarters of them not involving the ground [1]. This flashes category includes intracloud, intercloud, and cloud-to-air discharges (ICs), while the remaining quarter of the global flash activity includes the cloud-to-ground discharges (CGs) which are of major interest for the safety and integrity of buildings and structures.

A cloud-to-ground lightning flash usually consists of multiple single electric discharges namely "strokes", which, in turn, include two primary discharge processes, the downward-moving process termed as a leader and the upward-moving process termed as a return stroke. Based on the observations made by scientists and engineers all over the world about the polarity of the flash charge lowered to ground and the direction of the initial leader, four types of CGs have been identified and determined in international literature [1]. These types are referred to as: (a) downward negative lightning, (b) upward negative lightning, (c) downward positive lightning, and (d) upward positive lightning. From observations till now the scientific community remains convinced that nearly $90 \%$ of the global lightning discharges belongs to category (a) and less than $10 \%$ belongs to category (c). The particular type of upward flashes is met only in case of tall structures (higher than $100 \mathrm{~m}$ or so) or in case of objects lying on hill and mountain tops, such as the wind turbines of wind parks. The downward negative lightning flashes, thus, may be regarded as occupying a dominant position within the global lightning activity.

The main lightning current parameters as defined and reported in international standards and manuscripts $[2,3]$ are the peak current $I$, the front time $T_{1}$ and the time to half value $T_{2}$ on the tail of impulse current for short strokes, the duration time $T_{L O N G}$ and the long stroke charge $\mathrm{Q}_{\text {LONG }}$ for long strokes, and the specific energy $\mathrm{W} / \mathrm{R}$ and the flash charge $\mathrm{Q}$. The parameters of major interest for the lightning protection studies are I and $\mathrm{W} / \mathrm{R}$ related to mechanical effects of lightning, $\mathrm{W} / \mathrm{R}$ related to thermal effects of lightning when resistive coupling is involved and $Q$ related to thermal effects of lightning when arcs develop in the installation, and the average steepness di/dt of the impulse current front when overvoltages and hazardous sparking occur caused by inductive coupling. The severity of a lightning strike and the degree of damage it can cause to a structure itself and its contents depend on the position of the point of strike. According to IEC Std. [2] there are four categories of lightning strike affecting a structure: (a) direct lightning strike to the structure, (b) lightning strike near the structure, (c) direct lightning strike to the lines connected to the structure, and (d) lightning strike near the lines connected to the structure. Each situation depending on the lightning current parameters can cause injury to people and livestock, physical damage due to mechanical and thermal effects (fire, explosion, chemical release), and failure of internal systems due to lightning electromagnetic pulse (LEMP). All these categories are closely related to the present case study for wind farms investigated in this paper, as they may lead to one of the loss categories specified by IEC [2], i.e., loss of human life, loss of service to public, and loss of economic value. For this purpose, risk assessment must be considered corresponding to each type of loss, and the appropriate lightning protection measures have to be justified [4]. Four lightning protection levels (I to IV) have been introduced in general by international standardization, each one of them including a set of lightning current parameters values related to the probability that, in a natural lightning incidence, the corresponding maximum and minimum design values will not be exceeded.

The recording and measurement of cloud-to-ground lightning flashes began at the beginning of 1930s, when small magnetic links were employed to measure the current peak value using Ampere's law. These magnetic links consisting of small bundles of parallel steel wires were placed in glass tubes [3] and installed near down-conductor systems which are prone to be magnetized in case of a lightning incidence. In the same time period, 
measurements of lightning current at the Empire State Building in New York, USA provided the first recording of the lightning current waveform by means of an oscilloscope. To date, the measurements and recordings that constitute one of the cornerstones for understanding the peak current distribution are those conducted by Berger at two 70-m-high towers at the top of the mountain San Salvatore, Switzerland [5]. These research results [6] constituted the basis for lightning protection standardization until now. Similar direct and long-term measurements on high towers have been performed in several countries all over the world [7-11], investigating upward lightning flashes due to the height and the location of those structures. Further, upward lightning seems to be predominant in the case of wind turbines presented in this study, as they are installed at the top of mountains and hills of medium height with a tower height of 80-120 m.

More recent direct measurements of lightning current parameters have been presented by Visacro et al. [12], Takami and Okabe [13], and Diendofer et al. [14]. Measurements performed in the period 1985-1998 on the 60-m Morro do Cachimbo tower in Brazil employed two Pearson coils with a frequency of bandwidth ranging from $100 \mathrm{~Hz}$ to $10 \mathrm{MHz}$ connected to two oscilloscopes. The first coil was used for recording current waveforms above $20 \mathrm{kA}$ and the second one below $20 \mathrm{kA}$. Later, the recording system was upgraded by two new coils of larger bandwidth for measuring currents from $20 \mathrm{~A}$ to $200 \mathrm{kA}$. The direct measurements of lightning return-stroke currents conducted on 60 transmission towers mostly installed at a mountain ridge in Japan also employed two Rogowski coils with RC external integrators connected to 10-bit memory cards through shielded cables. The measuring system had a frequency bandwidth from $10 \mathrm{~Hz}$ to $1 \mathrm{MHz}$, enabling the recording of currents on two amplitude scales from \pm 10 to $\pm 300 \mathrm{kA}$. Besides the measurements on transmission towers, direct lightning current measurements are also performed at Tokyo Skytree, one of the tallest free-standing towers in the world serving as television, radio, and multimedia broadcast site for Tokyo area. The measuring system, installed at the top of the tower, also employs two types of Rogowski coils arranged in a polyvinyl chloride tube, with a frequency range of $0.5 \mathrm{~Hz}-250 \mathrm{kHz}$ for the first one, and $2 \mathrm{kHz}-5 \mathrm{MHz}$ for the second one [15-17]. The low frequency coil is used to provide the total shape of the current waveform, while the three high frequency coils are used to measure the peak current and the steepness of the front of the lightning current. Finally, there have been measurements at the 100-m Gaisberg tower in Austria [14] recording directly upward negative flashes. The corresponding measuring system consisted of a current-viewing resistor (shunt) of $0.25 \mathrm{~m} \Omega$ providing a bandwidth of $0 \mathrm{~Hz}$ to $3.2 \mathrm{MHz}$. In order to transmit the shunt output signal to a digital recorder located near the tower, fiber optic links were employed ending at two separate channels of different sensitivity. The signals were recorded via an 8-bit board installed in a pc.

Since the measuring systems in direct lightning current measurements follow more or less the same principle, e.g., Rogowski coil, fiber optic links, digital oscilloscopes, an attempt has been made in the last years for better designing and improving the efficiency of these systems. More particularly, a new experimental platform has been built in Shenzhen, China [18] in order to accurately measure not only the direct lightning current, but also light and surrounding electromagnetic fields of lightning flash through a meteorological gradient observation tower for research purpose of lightning physics. In the same period, other researchers developed a new flexible Rogowski coil with an active integrator for lightning current collection with good linearity and waveform restoration [19].

Though the direct current measurements on high towers stricken by flashes provide a full view of the natural phenomenon itself, this method trails significantly in terms of strike incidence numbers, as it is clearly referred to in all the aforementioned studies including a statistical analysis for current parameters presented by Heidler et al. [20]. Measurements on towers, hence, cannot provide a data sample sufficient for detailed waveform recording and robust conclusions. This data deficit is overcome by the rocket-triggered lightning method. Following this method, a rocket is launched against stormy clouds trailing an earthed metal wire into a strong electric field and, therefore, triggering upward discharges. 
Lightning channel-based currents are usually measured by noninductive shunts which are mounted on the rockets [21]. Such experiments are conducted in France [22], Japan [23-25], China [26-28], and the USA [29-31].

Besides the studies and experiments on direct lightning current measurements, remarkable work has been done on lightning location systems (LLSs) for mitigating threats from intracloud and cloud-to-ground lightning flashes. LLSs mainly consist of sensors for detecting and measuring the peak current value and the polarity of the flash localizing it simultaneously in space and time [32,33]. For GCs, particularly, studies have shown that the most powerful emissions for CG return strokes are in the LF and VLF range. Thus, a method for localizing lightning occurrence is by cross-checking the recorded data from a network of sensors working in the VLF/LF range. The two most common techniques for lightning localization are the magnetic direction finder (MDF) and time of arrival (TOA), which can also be applied in the VHF range [34]. Finally, the most recent research [35] shows that VHF is the most common frequency band for lightning localization and mapping, while the interferometer (ITF) is a potentially promising technique which can produce results of high accuracy in lightning mapping.

The installation of new wind farms leads to the need of designing and building suitable earthing systems, which will ensure their safe operation. To disperse lightning currents and prevent damage to a wind turbine, an efficient earthing system for the machine is essential. The wind turbine generator earthing system should provide sufficient protection against damage due to lightning flashes that correspond to the LPL (lightning protection level) for which the wind turbine protection system is designed. The earthing systems are required to ensure personnel safety with regard to the step and touch voltages appearing during earth faults, prevent damage to equipment, withstand the thermal and electrodynamic forces it will be subjected to during a fault, and have sufficient long-term mechanical strength and corrosion resistance [36].

The paper is structured concisely as follows: In Section 2 there is an analytical reference to the lightning recording stations of the examined wind parks and their location around Greece, the prevailing meteorological conditions over those areas and the lightning parameters the stations record and measure. Section 3.1 illustrates the recorded data of the lightning flash incidences for each wind farm and, through a detailed statistical analysis, provides important information and data about the lightning occurrence frequency over specific areas of the Hellenic territory either per year or per season. It also analyzes the variance in lightning occurrence per geographical region based on long-term meteorological data and previous climatic studies. In a similar way, Section 3.2 provides the measurement results of lightning current amplitude as recorded by the wind farm stations along with a statistical analysis featuring the positive and negative flashes per geographical region and season. Section 3.3 refers to the grounding systems of the wind farms, their role to the crucial issue of safety by dispersing the high lightning current into the earth with no hazard to people, livestock and equipment, their characteristics and parameters, the topology applied in modern constructions, and the significant magnitude of ground resistance. Finally, the concluding section summarizes all the critical data and information drawn from this research work, emphasizing its most important and useful findings.

The main goal of this study is to present a general view of the lightning activity over the Hellenic territory, based on a long-term recording and observation of lightning strikes upon wind turbines, providing engineers with significant data about the frequency and the polarity of flashes as well as the magnitude of the lightning current per geographical region, season, year, and the examined time period in total. Thus, this study highlights the frequent occurrence of lightning strikes on wind parks and the necessity of installing a lightning protection system. These data, along with the information provided for the grounding systems of the wind farms and the resistance they present at the various regions of the country, constitute firm and useful knowledge for electrical engineers in the field of wind farm constructions. At this point, nevertheless, it should be noted that the recorded lightning strikes presented in this paper are not related to the final location of a wind 
farm, as the procedure for defining the installation field is based primarily on the wind potential analysis of the candidate region. The lightning activity of the region is taken into consideration only during the risk assessment procedure and the design of the lightning protection system.

\section{Recording Stations and Data Acquisition}

The data presented in this work were recorded during the period 2011-2020 from ten (10) wind parks at several geographic regions of Greece (Figure 1). The recording sites are distributed around the country, in order to consider the different local climatic conditions. All the wind farms were in-line for the entire time period of recording and measurement. The Ionian islands at western Greece (WP1 and WP2) along with the NW mainland, namely Epirus and Western Macedonia (WP3-WP5), for instance, are crossing-regions of major importance for cyclonic systems (systems of low pressure) generated and coming from central Mediterranean Sea, moving towards NE Balkan Peninsula. These water-vaporenriched systems from the warm waters of the Ionian Sea cause severe stormy phenomena, characterized by frequent lightning occurrence in the western part of the country. Unlike western regions, the southern and eastern regions (WP6, WP8, WP9) suffer much less from storms and lightning occurrence. The regional gradient in flashes is also evident in the results.

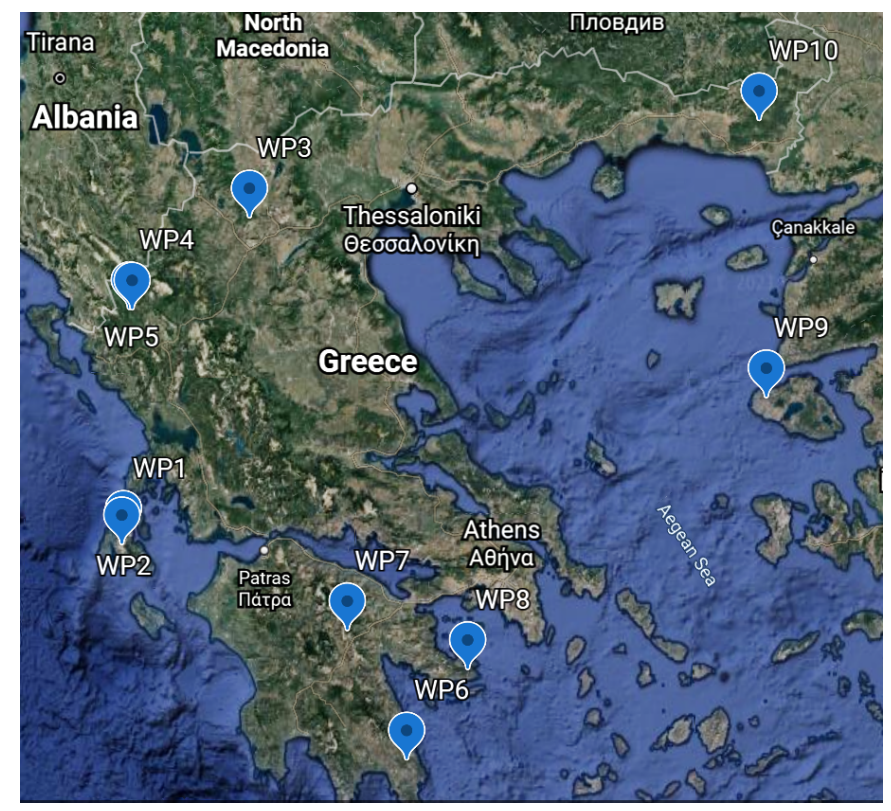

Figure 1. The locations of the 10 examined wind parks.

The lightning recording system at the aforementioned wind parks is the LINET Lightning Location System (LINET LLS) developed and operated by "nowcast GmbH", providing data like date and time, coordinates (latitude, longitude), amplitude and polarity of the lightning flash. Moreover, the recording system recognizes the type of lightning flash, e.g., cloud-to-cloud, intracloud, cloud-to-ground and gives information about the two-dimensional error of the reported location of the strike. LINET LLS is a high-resolution lightning detection system that detects the $3 \mathrm{D}$ emission height of cloud strokes. The detection system comprises of two modules: several lightning sensors and a central server. Each lightning sensor consists of one magnetic field antenna, a GPS module, and a field processor. The field processor receives and processes the antenna signals. It measures continuously after recognition of a lightning pulse and transmits the data to the central processing system via the internet. All lightning pulse parameters are stored locally.

Based on the timestamps of each recorded stroke, the position of the lightning stroke can be calculated via triangulation. At least 3 timestamps and 4 timestamps are required 
for the exact location of the lightning stroke in two and three dimensions, respectively. Lightning sensors are installed every $150-250 \mathrm{~km}$. On average, there are 4-6 sensors every $10^{5} \mathrm{~km}^{2}$ of measuring surface. The lightning detection efficiency of the LINET system for detecting strikes of a peak amplitude not lower than $3 \mathrm{kA}$ is at least $95 \%$ and even lower peak amplitude strikes can be detected. The average spatial error of the data obtained is $130 \mathrm{~m}$ for each of the wind farms under study.

In this study, only the cloud-to-ground flashes (CGs) are recorded, as intracloud flashes reach only up to a maximum value of $2 \%$ of the total recorded flashes in the examined wind parks and, furthermore, CGs are the main source of danger for living beings, structures, and equipment.

\section{Results and Discussion}

\subsection{Lightning Occurence Frequency}

In this section, the results of a detailed statistical analysis for the frequency of lightning occurrence and the mean amplitude of the lightning flashes at the considered wind parks are presented. The results are distinguished into positive and negative flashes in order to examine the behavior of each type of lightning separately and investigate the influence of various geographical and meteorological parameters on each single type. An important parameter determining both the lightning occurrence frequency and flash polarity is the average altitude of each single wind park, which is referenced in Table 1 . The average altitude is considered in this study, as the large majority of wind turbine generators of the examined parks are located at mountain crests. The lightning occurrence recorded in Tables $2-5$ aids the engineers to prepare a risk assessment per candidate location in order to make decisions on the final construction, while the mean current amplitude recorded in Tables 6, 7, A3 and A4 provides them with the necessary information in order to prepare proper studies for sufficient lightning protection measures and grounding.

Table 1. Average altitude of the location of each wind park.

\begin{tabular}{|c|c|c|c|c|c|c|c|c|c|c|}
\hline \multirow{2}{*}{ Altitude (m) } & WP1 & WP2 & WP3 & WP4 & WP5 & WP6 & WP7 & WP8 & WP9 & WP10 \\
\hline & 1030 & 960 & 1900 & 680 & 750 & 810 & 1590 & 450 & 470 & 600 \\
\hline
\end{tabular}

Table 2. Annual recorded positive lightning strikes per wind park presented as actual numbers $(\mathrm{N})$ and as percentage of the total annual strikes (\%) (observation period 2011-2020).

\begin{tabular}{|c|c|c|c|c|c|c|c|c|c|c|c|c|c|c|c|c|c|c|c|c|}
\hline \multirow[t]{2}{*}{ Year } & \multicolumn{2}{|c|}{ WP1 } & \multicolumn{2}{|c|}{ WP2 } & \multicolumn{2}{|c|}{ WP3 } & \multicolumn{2}{|c|}{ WP4 } & \multicolumn{2}{|c|}{ WP5 } & \multicolumn{2}{|c|}{ WP6 } & \multicolumn{2}{|c|}{ WP7 } & \multicolumn{2}{|c|}{ WP8 } & \multicolumn{2}{|c|}{ WP9 } & \multicolumn{2}{|c|}{ WP10 } \\
\hline & $\mathbf{N}$ & (\%) & $\mathbf{N}$ & (\%) & $\mathbf{N}$ & $(\%)$ & $\mathbf{N}$ & $(\%)$ & $\mathbf{N}$ & $(\%)$ & $\mathbf{N}$ & (\%) & $\mathbf{N}$ & $(\%)$ & $\mathbf{N}$ & $(\%)$ & $\mathbf{N}$ & $(\%)$ & $\mathbf{N}$ & $(\%)$ \\
\hline 2011 & 7 & 5.9 & 18 & 22.8 & 53 & & 54 & 21.4 & 26 & 25. & 0 & 0 & 2 & & 1 & 25.0 & 0 & 0.0 & 7 & 15.6 \\
\hline & 25 & & & & & & & & & & & & & & & & & & & 24.1 \\
\hline & 8 & & 6 & & & & & & & & 2 & & & & & & & & & \\
\hline & 26 & & 16 & & & & & & 4 & & 0 & & 1 & & $?$ & & 3 & & & 24.8 \\
\hline & 35 & 1 & 32 & 5.9 & & 23 & 200 & & 80 & & 5 & & 13 & & 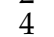 & & 10 & & 82 & 29.5 \\
\hline & 35 & & & & & & & & & & 12 & & & & & & 11 & & & 42.0 \\
\hline & 37 & & 25 & 16. & 9 & & 15 & & 6 & 29 & 2 & & 10 & & 2 & & 0 & & & 32.8 \\
\hline & & & 7 & & & & & & 10 & & 1 & & 8 & & & & 2 & & & 21.3 \\
\hline & 131 & & 87 & 38.8 & & 19 & 317 & 26 & 93 & 31 & 5 & & 4 & 2. & & & 1 & & 7 & 42.7 \\
\hline & 16 & 15.8 & 9 & 37.5 & 112 & 20.1 & 121 & 16.6 & 73 & 18.7 & 1 & 33.3 & 1 & 3.6 & 1 & 50.0 & 6 & 20.0 & 220 & 29.1 \\
\hline $\begin{array}{l}\text { Global } \\
\text { mean }\end{array}$ & 33.7 & 16.9 & 27.7 & 22.4 & 126.9 & 20.0 & 161.2 & 24.9 & 65.3 & 24.4 & 2.8 & 22.3 & 5.8 & 9.5 & 2 & 25.9 & 4.5 & 21.9 & 120.2 & 27.7 \\
\hline
\end{tabular}


Table 3. Annual recorded negative lightning strikes per wind park presented as actual numbers $(\mathrm{N})$ and as percentage of the total annual strikes (\%) (observation period 2011-2020).

\begin{tabular}{|c|c|c|c|c|c|c|c|c|c|c|c|c|c|c|c|c|c|c|c|c|}
\hline \multirow[t]{2}{*}{ Year } & \multicolumn{2}{|c|}{ WP1 } & \multicolumn{2}{|c|}{ WP2 } & \multicolumn{2}{|c|}{ WP3 } & \multicolumn{2}{|c|}{ WP4 } & \multicolumn{2}{|c|}{ WP5 } & \multicolumn{2}{|c|}{ WP6 } & \multicolumn{2}{|c|}{ WP7 } & \multicolumn{2}{|c|}{ WP8 } & \multicolumn{2}{|c|}{ WP9 } & \multicolumn{2}{|c|}{ WP10 } \\
\hline & $\mathbf{N}$ & $(\%)$ & $\mathbf{N}$ & $(\%)$ & $\mathbf{N}$ & $(\%)$ & $\mathbf{N}$ & $(\%)$ & $\mathbf{N}$ & $(\%)$ & $\mathbf{N}$ & $(\%)$ & $\mathbf{N}$ & $(\%)$ & $\mathbf{N}$ & $(\%)$ & $\mathbf{N}$ & $(\%)$ & $\mathbf{N}$ & $(\%)$ \\
\hline 2011 & 111 & 041 & 85 & 77.2 & 517 & & 198 & 786 & 78 & 75.0 & 2 & & 62 & & 3 & 75.0 & 2 & 100 & 38 & 84.4 \\
\hline & & & 76 & & & & & & 78 & & & & & & & & 1 & & & \\
\hline & 121 & 93.8 & 67 & 90 & & 90 & 34 & 75 & 178 & 83 & 5 & & 12 & 70 & 2 & 50 & 2 & & 20 & 4.5 \\
\hline & 116 & 81.7 & 87 & & & & 30 & & 121 & & 10 & & 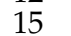 & 93.8 & 11 & & 42 & & 366 & 75.2 \\
\hline & 158 & 81.9 & 190 & & & 76 & 57 & 74. & 343 & 81 & 15 & & & 82.2 & 18 & & 14 & & 196 & 70.5 \\
\hline & 196 & 84.8 & 270 & 77.1 & 85 & 76 & 48 & 65 & 369 & 77 & 21 & & 151 & 93.8 & 13 & 92 & 16 & 59 & 11 & 58.0 \\
\hline & & & 158 & & & & 38 & 71 & 154 & & 2 & & & 91 & 2 & & 2 & & & 67.2 \\
\hline & 77 & 81.9 & 45 & 84.4 & 484 & 76 & 585 & 73. & 255 & 71 & 2 & 66 & 110 & 93.2 & 13 & 81 & 18 & 90.0 & 651 & 78.7 \\
\hline 201 & 263 & 66.8 & 224 & 61.2 & 982 & 81.0 & 867 & 73.2 & 206 & 68 & 25 & & 193 & 98.0 & 12 & 75.0 & 2 & 66.7 & 345 & 57.3 \\
\hline & 85 & 84.2 & 24 & 62.5 & 445 & 79.9 & 606 & 83.4 & 317 & 81.3 & 2 & 66.7 & 27 & 96.4 & 1 & 50.0 & 24 & 80.0 & 536 & 70.9 \\
\hline $\begin{array}{l}\text { Global } \\
\text { mean }\end{array}$ & 139 & 83.1 & 122.6 & 77.6 & 525.6 & 80.0 & 470 & 75.1 & 209.9 & 75.6 & 8.5 & 77.7 & 76.3 & 90.5 & 7.6 & 74.1 & 12.3 & 78.1 & 286.3 & 72.3 \\
\hline
\end{tabular}

Table 4. Mean monthly number (observation period 2011-2020) of recorded positive lightning strikes per wind park and global mean per wind park and month.

\begin{tabular}{cccccccccccc}
\hline Month & WP1 & WP2 & WP3 & WP4 & WP5 & WP6 & WP7 & WP8 & WP9 & WP10 & Global Mean \\
\hline January & 1.8 & 2.5 & 0.1 & 1.5 & 0.7 & 0 & 0 & 0.3 & 0.3 & 2.7 & 1.0 \\
February & 1.5 & 0.9 & 0.7 & 3.7 & 2.3 & 0 & 0.4 & 0.2 & 0.4 & 1.0 & 1.1 \\
March & 0.7 & 0.1 & 0.1 & 2.1 & 0.9 & 0 & 0 & 0 & 0 & 2.2 & 0.6 \\
April & 0.2 & 0.4 & 2.2 & 3.6 & 2.2 & 0 & 0 & 0 & 0.6 & 4.6 & 1.4 \\
May & 0.3 & 0.4 & 19.7 & 13.5 & 4.7 & 0 & 0.7 & 0 & 0 & 15.9 & 5.5 \\
June & 1.1 & 1.1 & 25.2 & 13.4 & 9.8 & 0.1 & 1.1 & 0.2 & 0.6 & 41.5 & 9.4 \\
July & 1.1 & 0.5 & 22.8 & 30.0 & 12.8 & 0.1 & 1.0 & 0 & 0 & 31.5 & 10.0 \\
August & 0.6 & 0.6 & 38.8 & 30.9 & 11.1 & 0.2 & 0.7 & 0.1 & 0.1 & 8.8 & 9.2 \\
September & 5.7 & 7.3 & 11.9 & 30.5 & 9.9 & 1.3 & 0.9 & 0.2 & 0.9 & 2.4 & 7.1 \\
October & 12.2 & 9.6 & 2.3 & 11.5 & 3.7 & 0.2 & 0.8 & 0.1 & 0 & 7.1 & 4.8 \\
November & 6.2 & 2.8 & 2.1 & 14.6 & 4.4 & 0.7 & 0.2 & 0.5 & 1.3 & 1.7 & 3.5 \\
December & 2.3 & 1.5 & 1.0 & 5.9 & 2.8 & 0.2 & 0 & 0.4 & 0.3 & 0.8 & 1.5 \\
Global & 2.81 & 2.31 & 10.58 & 13.43 & 5.44 & 0.23 & 0.48 & 0.17 & 0.38 & 10.02
\end{tabular}

Table 5. Mean monthly number (observation period 2011-2020) of recorded negative lightning strikes per wind park and global mean per wind park and month.

\begin{tabular}{cccccccccccc}
\hline Month & WP1 & WP2 & WP3 & WP4 & WP5 & WP6 & WP7 & WP8 & WP9 & WP10 & Global Mean \\
\hline January & 22.1 & 7.0 & 0 & 2.1 & 0.8 & 0.5 & 5.3 & 1.0 & 1.1 & 7.6 & 4.8 \\
February & 8.4 & 3.4 & 2.6 & 7.8 & 5.5 & 0.1 & 1.8 & 0.2 & 0.6 & 6.8 & 3.7 \\
March & 7.9 & 0.9 & 5.1 & 8.0 & 3.1 & 0 & 1.5 & 0 & 0.2 & 6.3 & 3.3 \\
April & 1.1 & 0.8 & 5.6 & 9.0 & 6.7 & 0 & 0.7 & 0 & 0.7 & 12.2 & 3.7 \\
May & 2.2 & 2.3 & 65.1 & 40.1 & 14.4 & 0.9 & 6.0 & 0.1 & 0.1 & 44.5 & 17.6 \\
June & 5.5 & 4.0 & 96.0 & 43.4 & 31.6 & 0.3 & 9.0 & 1.0 & 1.8 & 81.8 & 27.4 \\
July & 3.7 & 4.3 & 89.4 & 106.4 & 36.1 & 0.2 & 10.4 & 0.2 & 0.2 & 73.7 & 32.5 \\
August & 6.4 & 3.2 & 159.5 & 94.2 & 41.7 & 0 & 7.7 & 0.6 & 1.0 & 14.2 & 32.9 \\
September & 20.0 & 23.3 & 68.9 & 81.9 & 31.7 & 3.6 & 15.3 & 1.4 & 0.7 & 9.8 & 25.7 \\
October & 33.2 & 28.8 & 6.1 & 39.1 & 21.1 & 1.2 & 9.6 & 0.8 & 1.8 & 18.0 & 16.0 \\
November & 18.5 & 8.2 & 24.8 & 22.0 & 11.7 & 1.7 & 6.5 & 1.3 & 2.9 & 8.4 & 10.6 \\
December & 10.0 & 5.1 & 2.5 & 16.0 & 5.5 & 0 & 2.5 & 1.0 & 1.2 & 3.0 & 4.7 \\
Global & 11.58 & 7.61 & 43.80 & 39.17 & 17.49 & 0.71 & 6.36 & 0.63 & 1.03 & 23.86 & \\
mean & & & & & & & & & & &
\end{tabular}


Table 6. Annual average amplitude $(\mathrm{kA})$ of the recorded positive lightning strikes per wind park (observation period 2011-2020).

\begin{tabular}{ccccccccccc}
\hline \multirow{2}{*}{ Year } & \multicolumn{8}{c}{ Average Amplitude (kA) of Positive Lightning Strikes } \\
\cline { 2 - 11 } & WP1 & WP2 & WP3 & WP4 & WP5 & WP6 & WP7 & WP8 & WP9 & WP10 \\
\hline 2011 & 25.23 & 19.92 & 12.33 & 17.03 & 22.57 & 0.00 & 15.75 & 25.60 & 0.00 & 15.76 \\
2012 & 20.39 & 16.06 & 11.36 & 15.48 & 23.05 & 0.00 & 27.20 & 0.00 & 0.00 & 43.74 \\
2013 & 58.78 & 46.43 & 14.28 & 22.57 & 19.45 & 20.10 & 73.48 & 65.30 & 62.95 & 19.79 \\
2014 & 16.61 & 37.39 & 19.21 & 15.41 & 15.75 & 0.00 & 17.60 & 24.40 & 11.12 & 11.66 \\
2015 & 17.17 & 24.01 & 10.25 & 16.43 & 13.59 & 20.08 & 29.58 & 23.34 & 24.66 & 11.26 \\
2016 & 18.84 & 10.86 & 8.95 & 10.92 & 10.33 & 14.33 & 11.34 & 52.30 & 6.90 & 10.48 \\
2017 & 20.83 & 23.28 & 12.57 & 9.40 & 11.43 & 18.55 & 21.76 & 16.15 & 0.00 & 9.98 \\
2018 & 24.14 & 37.53 & 8.91 & 10.66 & 9.07 & 20.00 & 24.34 & 14.77 & 17.25 & 10.06 \\
2019 & 16.32 & 14.95 & 9.52 & 10.02 & 9.48 & 20.54 & 23.15 & 15.23 & 28.90 & 6.60 \\
2020 & 7.91 & 7.73 & 11.25 & 8.17 & 8.85 & 10.30 & 31.80 & 18.30 & 12.47 & 8.03 \\
Global & 22.62 & 23.82 & 11.86 & 13.61 & 14.36 & 12.39 & 27.60 & 25.54 & 16.43 & 14.74 \\
mean & & & & & & & & & & \\
\hline
\end{tabular}

Table 7. Annual average amplitude (kA) of the recorded negative lightning strikes per wind park (observation period 2011-2020).

\begin{tabular}{ccccccccccc}
\hline \multirow{2}{*}{ Year } & \multicolumn{8}{c}{ Average Amplitude (kA) of Negative Lightning Strikes } \\
\cline { 2 - 10 } & WP1 & WP2 & WP3 & WP4 & WP5 & WP6 & WP7 & WP8 & WP9 & WP10 \\
\hline 2011 & 21.76 & 24.30 & 14.45 & 18.96 & 19.04 & 21.05 & 20.88 & 19.47 & 16.60 & 15.60 \\
2012 & 18.68 & 21.86 & 14.68 & 16.70 & 15.48 & 43.10 & 19.93 & 26.10 & 20.30 & 17.23 \\
2013 & 19.24 & 22.60 & 14.70 & 18.34 & 18.08 & 40.24 & 18.20 & 17.35 & 15.80 & 18.30 \\
2014 & 22.19 & 24.72 & 15.10 & 17.60 & 16.82 & 22.01 & 16.73 & 18.33 & 16.37 & 14.97 \\
2015 & 19.48 & 22.44 & 14.13 & 15.36 & 16.57 & 19.16 & 21.33 & 25.21 & 16.84 & 11.94 \\
2016 & 14.66 & 15.36 & 12.24 & 13.77 & 13.70 & 16.22 & 15.78 & 23.65 & 17.00 & 10.53 \\
2017 & 17.32 & 17.13 & 10.30 & 12.55 & 11.18 & 19.30 & 16.72 & 44.95 & 5.85 & 11.10 \\
2018 & 13.59 & 17.15 & 10.95 & 12.66 & 13.79 & 9.90 & 22.26 & 15.51 & 20.24 & 15.41 \\
2019 & 12.80 & 15.71 & 10.59 & 13.76 & 11.46 & 25.00 & 15.26 & 17.18 & 14.15 & 12.01 \\
2020 & 15.27 & 12.54 & 10.83 & 11.63 & 11.51 & 15.95 & 16.42 & 20.30 & 15.00 & 12.14 \\
Global & 17.50 & 19.38 & 12.80 & 15.13 & 14.76 & 23.19 & 18.35 & 22.81 & 15.82 & 13.92 \\
mean & & & & & & & & & &
\end{tabular}

Studying the findings of the above tables, it is evident that the WP3, WP4, WP5, and WP10 receive the lion's share in lightning activity among the 10 parks, followed by the WP1 and WP2. The records confirm the initial claim that the western and NW regions experience severe stormy phenomena rich in lightning discharges. The negative flash is clearly the dominant type of lightning strikes at all parks according to the much higher values of 10-year global mean of recorded strikes of Table 3 compared to the values of Table 2, although the wind turbine generators are tall structures installed at mountain crests and, therefore, more vulnerable to positive discharges. This fact seems clearer from the data of Appendix A, Table A1, which gives the positive and negative flashes as a percentage of the total lightning flashes per wind farm, as well as from the 10 farms in total. Meanwhile, as extracted from Tables 2 and 3, the percentage of positive CG flashes for the examined wind parks ranges from $7.06 \%$ up to $29.57 \%$, while the corresponding percentage of negative strikes varies from $70.43 \%$ up to $92.94 \%$.

There are obviously several other situations, including, for example, seasonality, which appear to affect lightning occurrence frequency every year. The summer storms occurring at regions near the sea are very rich of lightning incidences, probably because of the abundant content in ions of water vapor in stormy clouds coming from the warm waters of the Mediterranean Sea through evaporation and the reduced content in humidity molecules of the atmospheric air between cloud and ground favoring lightning 
activity. This will become more evident from the monthly statistics of each park in the following tables.

In order to visualize the findings of the Tables 2 and 3 and obtain a comprehensive picture for the annual lightning activity at each park, the relative frequency of annual lightning discharges for the ten examined parks is illustrated in Figures 2 and 3, displaying the relative share of the annual positive and negative strikes of each park as a percentage of the total corresponding strikes recorded at all parks per year.

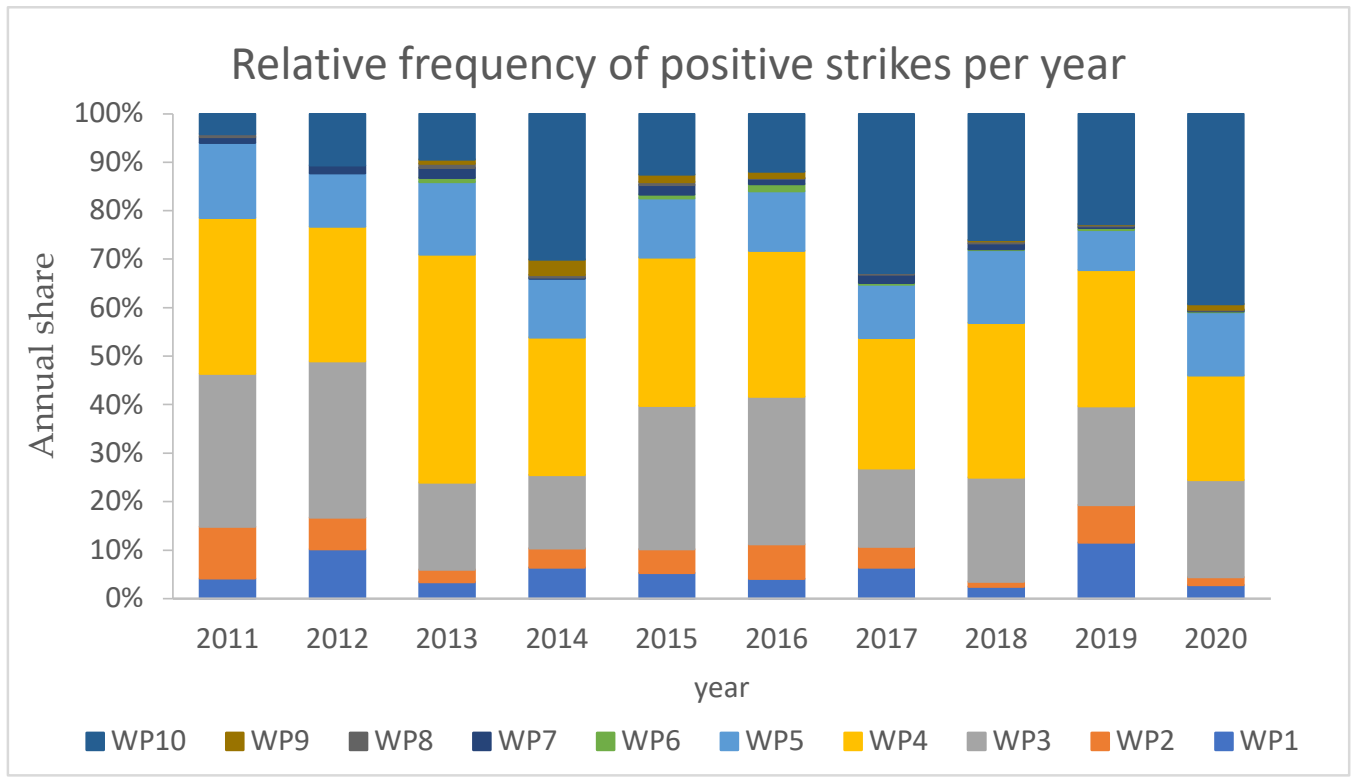

Figure 2. Relative share of the annual positive strikes of each wind park as a percentage of the total positive strikes recorded per year.

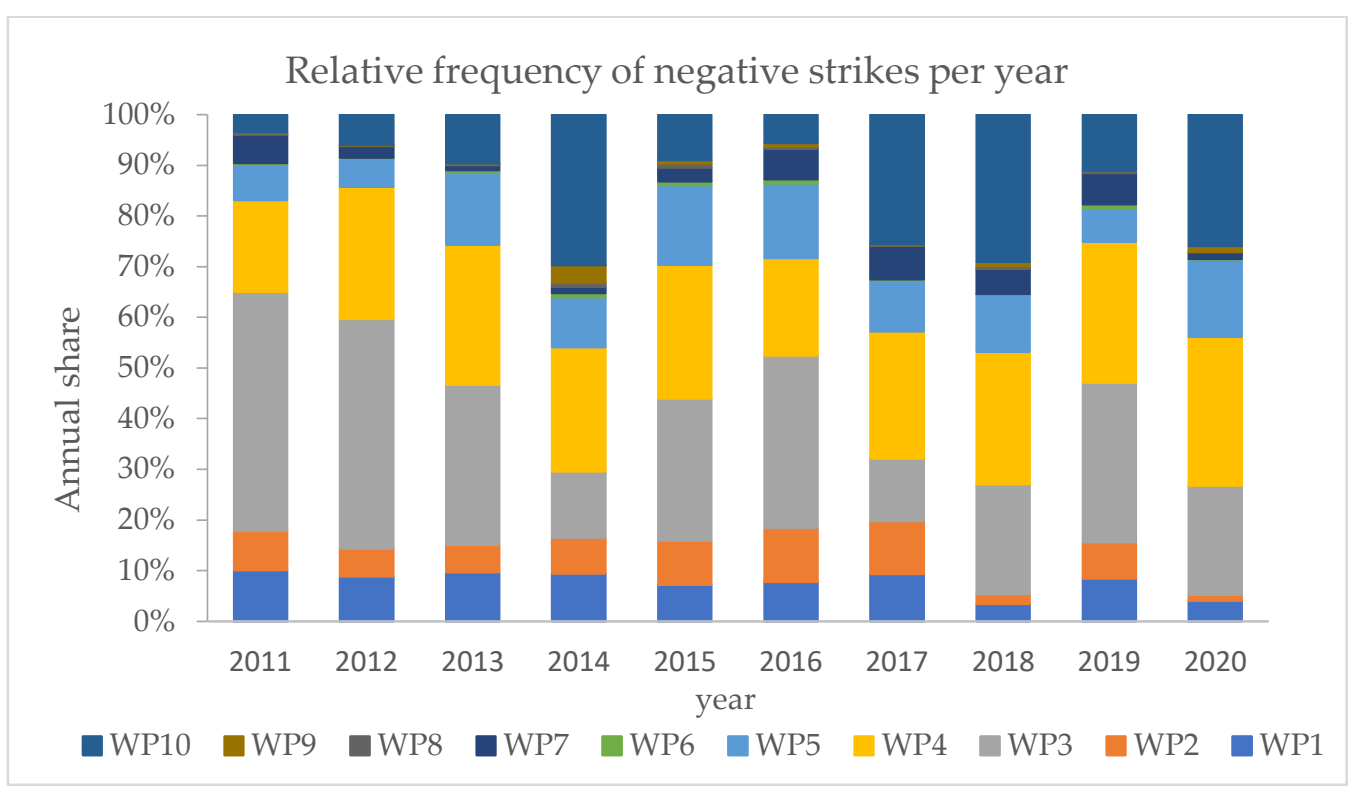

Figure 3. Relative share of the annual negative strikes of each wind park as a percentage of the total negative strikes recorded per year.

As it can be observed from the above graphs, the WP3 and WP4 accounts for $50 \%$ or slightly more of the annual positive lightning flashes all over the country for most of the years in the examined period and, definitely, much more than $50 \%$ in the case of negative flashes. If the relative share of the WP5 is added to that of the WP3 and WP4 together, then the relative share of just the three parks at the same region, i.e., a single geographical 
region, reaches $70-80 \%$ of the total lightning activity in the Hellenic territory for both cases of positive and negative polarity. It is also observed that the relative shares of the WP3 and WP5 vary inversely to the relative one of WP10 for some years in the examined period. This probably happens due to the diverging path the cyclonic systems follow from the west to the NE. It is worth mentioning, therefore, that the overwhelming majority of the strikes are concentrated in a wide geographical region in the NW of the Hellenic mainland, a fact of major importance for future similar projects at that area.

More specific information can be drawn from the following Tables 4 and 5 which contain the monthly average number of the recorded positive and negative lightning strikes, respectively, for each wind park, estimated from the whole 10-year period.

At first glance, the data tabulated in Tables 4 and 5 confirm the information drawn from Figures 2 and 3 about the lightning activity at the WP3, WP4, WP5, and WP10. In the monthly levels, both the WP3 and WP4 also present around 50\% of the total recorded lightning strikes at the Hellenic territory and, considering the strikes at the WP10, this percentage reaches $70 \%$ to $74 \%$ for both positive and negative polarity. The new element emerging from the above data is the noticeably increased lightning occurrence in the summer months, specifically, from May to September over the wind parks of the northern and NW Hellenic mainland (WP3, WP4, WP5, and WP10). This fact becomes more obvious, especially for positive lightning flashes, looking at the data of these parks, but certainly refers to both positive and negative discharges with different frequencies. Unlike mainland areas, the lightning activity over sea, islands, and coastline of western Greece appears to increase in autumn (for more information see Table A2).

The differentiation of seasonal and monthly lightning activity over the aforementioned regions is related to the prevailing meteorological conditions during autumn and summer that trigger the different generation mechanisms of thunderstorms [34]. The summer months are characterized by unstable weather conditions over the Hellenic mainland due to thermal convection as thunderstorms are of continental origin and, hence, lightning activity is related to this meteorological situation. During this phenomenon, solar irradiance warms the ground rapidly, especially in the warmest period of the day (noon to afternoon), triggering thermal convection i.e., sensible heat fluxes from the land to the upper atmospheric layers, which is enhanced by converging winds from the Ionian Sea (NW winds) and the Aegean Sea (NE winds) [34,35]. This phenomenon often leads to thunderstorm cloud formation of vertical development (cumulonimbus) which is rich in lightning discharges. The autumn months are characterized by unstable weather conditions over the sea; thus, autumn seems to be the favorable season for lightning activity over islands and coastlines. The maximum surface temperature of the sea is detected in September; therefore, there is a strong interaction between the warm sea and the troposphere taking place with sensible heat fluxes from the warm sea body of the Ionian Sea to the upper layers of troposphere. This heat flux is also combined with the invasion of cold and dry air masses coming from central Europe leading to significant cyclonic systems. The maximum lightning activity is detected over the Ionian Sea in autumn as it is the most active cyclone season, where the low-pressure systems are blocked by the Pindos mountains [35].

\subsection{Lightning Current Amplitude}

The next magnitude of major importance for designing LPS is the peak current of lightning flashes. The data obtained from the constant lightning recording at the ten wind parks, after the proper statistical process, are tabulated in Tables 6, 7, A3 and A4, and the respective graphs are illustrated in Figures 4 and 5. 


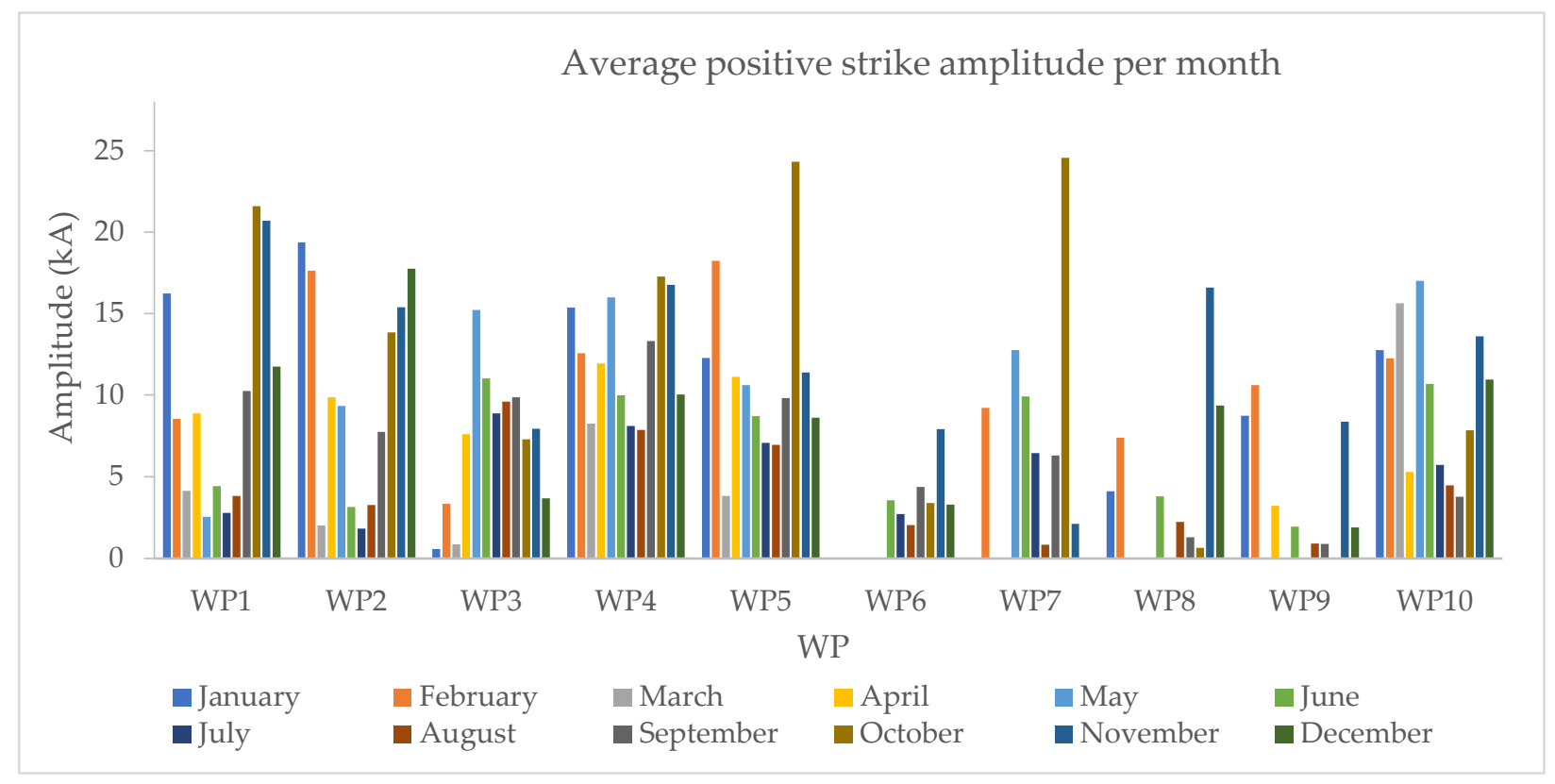

Figure 4. Monthly average amplitude (kA) of the recorded positive strikes of each wind park (observation period 2011-2020).

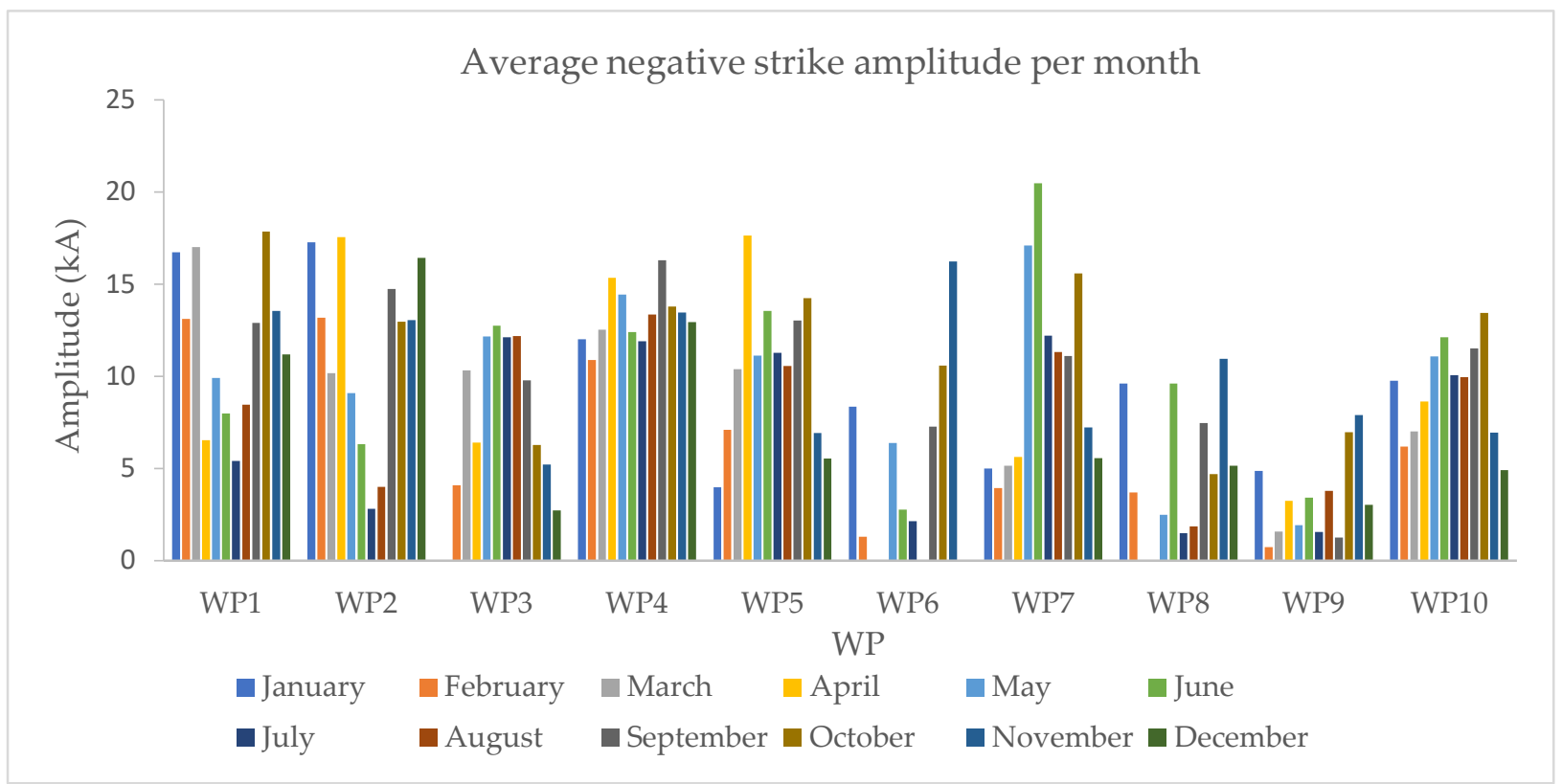

Figure 5. Monthly average amplitude $(\mathrm{kA})$ of the recorded negative strikes of each wind park (observation period 2011-2020).

The data in Tables 6 and 7 present higher values of current amplitude for positive lightning flashes than the respective ones for negative flashes, with the exception of WP6 where the current presents a large difference in value between the two polarities. The measurement results of the present study are in agreement with the global observations of Berger [5,6] and other researchers referenced in CIGRE TB [1] and IEC Std. [2]. At this point, it is noteworthy that the parks, which experience low lightning occurrence e.g., WP1, WP2, WP7, or WP8 according to Tables 2 and 3, appear to suffer from relatively high amplitude currents observing the total mean values for each park in Tables 6 and 7. This means that the probability for these parks to experience a severe and hazardous lightning strike regarding the current amplitude is much higher than the other parks, despite their low lightning occurrence frequency. This fact has certainly the proportional impact on 
the risk assessment for the examined structures and the necessary enhanced protection measures that must be taken.

A better image for the distribution of current amplitude per wind farm during the year is drawn from the graphs of Figures 4 and 5 and the data tabulated in Tables A3 and A4.

Positive CG lightning flashes present the highest monthly mean values of peak current mainly between October and January in most examined locations. These values reach the level of $25 \mathrm{kA}$ and are detected over the WP5 and WP7 both in October. WP1 follows with the highest monthly mean value of peak current at $21.57 \mathrm{kA}$ also detected in October. On the other hand, the negative discharges present lower single peaks than the positive ones, e.g., the peak current detected over WP7 reaches $20.47 \mathrm{kA}$, but the global mean of negative flashes seems to be higher than the respective positive one for the $80 \%$ of the examined parks. Furthermore, the peak current distribution of positive discharges presents a higher standard deviation compared to that of negative flashes whose current values are clustered closely around the mean value. Besides, this explains the large difference between the upper and lower limits in some cases such as WP7 (upper limit of $24.54 \mathrm{kA}$, lower limit of $0.83 \mathrm{kA}$ ) or WP1 (upper limit of $21.57 \mathrm{kA}$, lower limit of $2.55 \mathrm{kA}$ ).

The graphs in Appendix A, Figures A1-A10 regarding the probability distribution of positive and negative lightning current amplitude for each single wind farm provide a clearer image of the current amplitude range which prevails in each polarity of CG flashes.

The amplitude probability distributions vary with location and season as can be seen in Figures 4 and 5. In most cases of parks it is observed that positive lightning flashes exhibit higher peak values against negative ones up to the limit of $10 \mathrm{kA}$ and then take again the reigns after $25 \mathrm{kA}$, unlike the negative flashes, which seem to prevail in the range of 10-25 kA. The general rule of major positive lightning occurrence upon very tall structures or building on the top of hills and mountains, however, does not apply in the cases of this study, as a large number of negative strikes have been observed upon wind turbine generators in the examined time period. This fact probably has to do with the generation mechanisms of thunderstorm clouds which may determine the bulk of positive and negative electric charge they contain and its distribution inside the clouds. These mechanisms need further observation and investigation through atmospheric measurements and analysis.

Finally, Figure 6 illustrates the amplitude probability distribution from the total of the ten (10) WPs providing interested parties with useful data about the lightning current amplitude for the largest part of the Hellenic territory. Data statistics show clearly that positive strikes dominate in the low current amplitude range, while negative ones are in the running from $10 \mathrm{kA}$ and beyond.

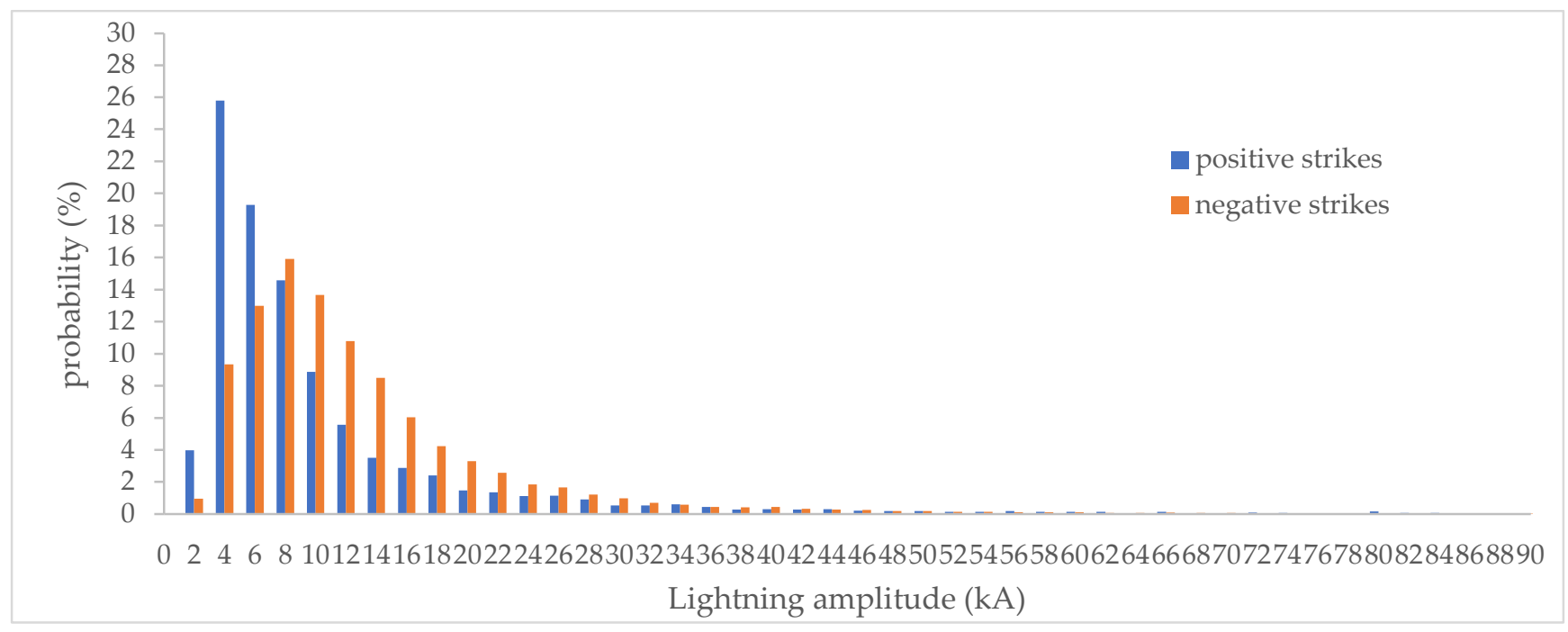

Figure 6. Amplitude probability distribution from the total of the ten (10) WPs within Hellenic territory. 


\subsection{Wind Farm Earthing Systems}

In order to design and model the earthing system, it is necessary to determine the standard the grounding system will be designed in accordance with, and to specify the elements required for the simulation, like the type of soil (bilayer, triple layer, etc.) to be used in modeling, soil morphology, fault current (maximum value, fault duration, frequency), and human weight (to be found at fault location), as well as the budget available for design-construction.

The earthing system should protect people and livestock against electric shock. In Greece the mean annual number of human deaths due to lightning activity is equal to 2 based on research statistics for the period 2000-2013 [34,37] and, more specifically, fatalities/injuries values are estimated to $2.00 / 1.57$, respectively. During fault occurrence in the electrical grid, it is necessary to keep the touch and step voltages and the overall earth potential rise to a safe level until protection devices have tripped and safely interrupted the flow of fault current. For lightning flashes, the earthing system must disperse and conduct high frequency and high energy lightning current into the earth without any dangerous thermal and/or electrodynamic effects.

IEEE Std. 80 [38], IEEE Std. 81 [39], and EN 50522 [40] describe methods for measuring soil resistivity and ground resistance, methodology for designing a grounding system, as well as methods for calculating step and touch voltages. Standard IEC 61400-24 [36] refers to the requirements of lightning protection of wind turbines.

Wind farms are usually installed at mountainous areas, where soil resistivity and, consequently, ground resistance of grounding systems present high values. Thus, it is necessary to develop alternative ways of strengthening and extending the grounding system of wind turbines, depending on the soil structure and the value of soil resistivity, aiming to reduce the ground resistance on the one hand and to eliminate the off-limit values of step voltages and touch voltages on the other hand.

Figures 7 and 8 display the total of ground resistance measurements carried out by the High Voltage Laboratory of the National Technical University of Athens at more than 550 wind turbine generators of wind farms within the Hellenic territory since 2002. It is obvious that the ground resistance of the wind turbines at specific geographic areas reaches high values. More specifically, $2 \%$ of the wind turbines have a ground resistance value of less than $1 \Omega$, while only $32 \%$ have a ground resistance value of less than $10 \Omega$. The design of the appropriate earthing system aims not only to limit the value of the ground resistance (which unfortunately in most cases has a value higher than of $10 \Omega$ ), but also in the elimination of the off-limit values of step and touch voltages. The $10 \Omega$ value is generally considered as the upper resistance limit a grounding system should ideally reach in order to provide sufficient protection against lightning flashes and to be able to correspond to the LPL for which the wind turbine protection system is designed [41]. Though most of the wind turbine earthing systems constructed in Greece in the past years present ground resistance greater than $10 \Omega$, no off-limits step and touch voltages have been developed (after the proper design of the earthing system). The safe operation of wind turbines (some are now approaching twenty years of operation) proves the accuracy, reliability, and usefulness of the respective measurements and studies.

The enhancement of the foundation earthing system should be accomplished in such a way as to minimize the additional construction costs. The available field area around a wind turbine is utilized for the extension of the perimeter grounding system as shown in Figure 9. Ground rods are used in case that soil resistivity value decreases in lower soil layers. Steady state ground resistance depends on the total surface area of the earthing system and the total length of the conductors; the outer loop and the thickening of the foundation grounding system, therefore, lead to a ground resistance value reduction and, consequently, to a step and touch voltages decrease. The choice of the appropriate way to reduce the ground resistance is confirmed using appropriate software. 


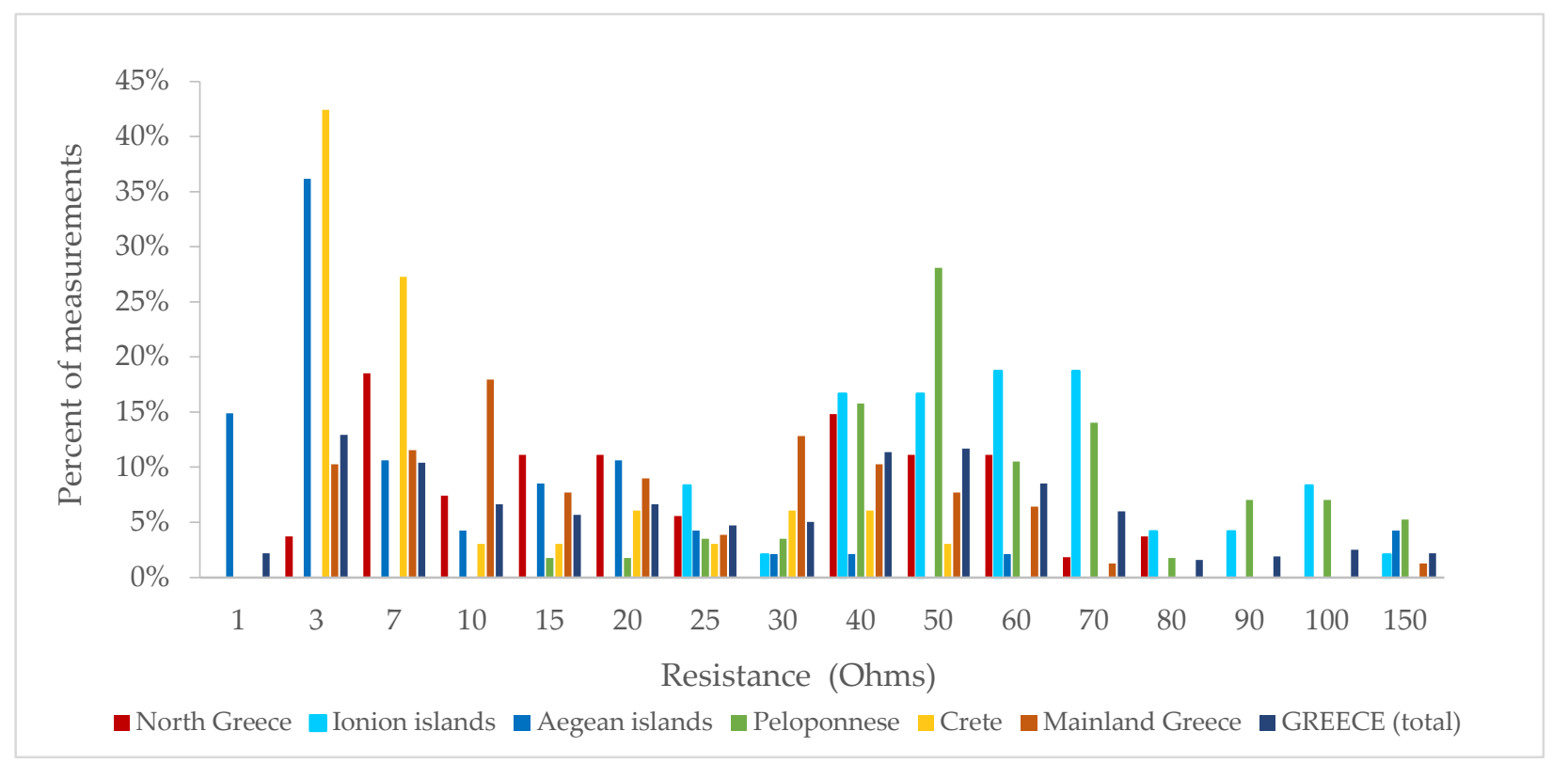

Figure 7. Percent of wind turbine earthing resistance measurements per geographical department of Greece.

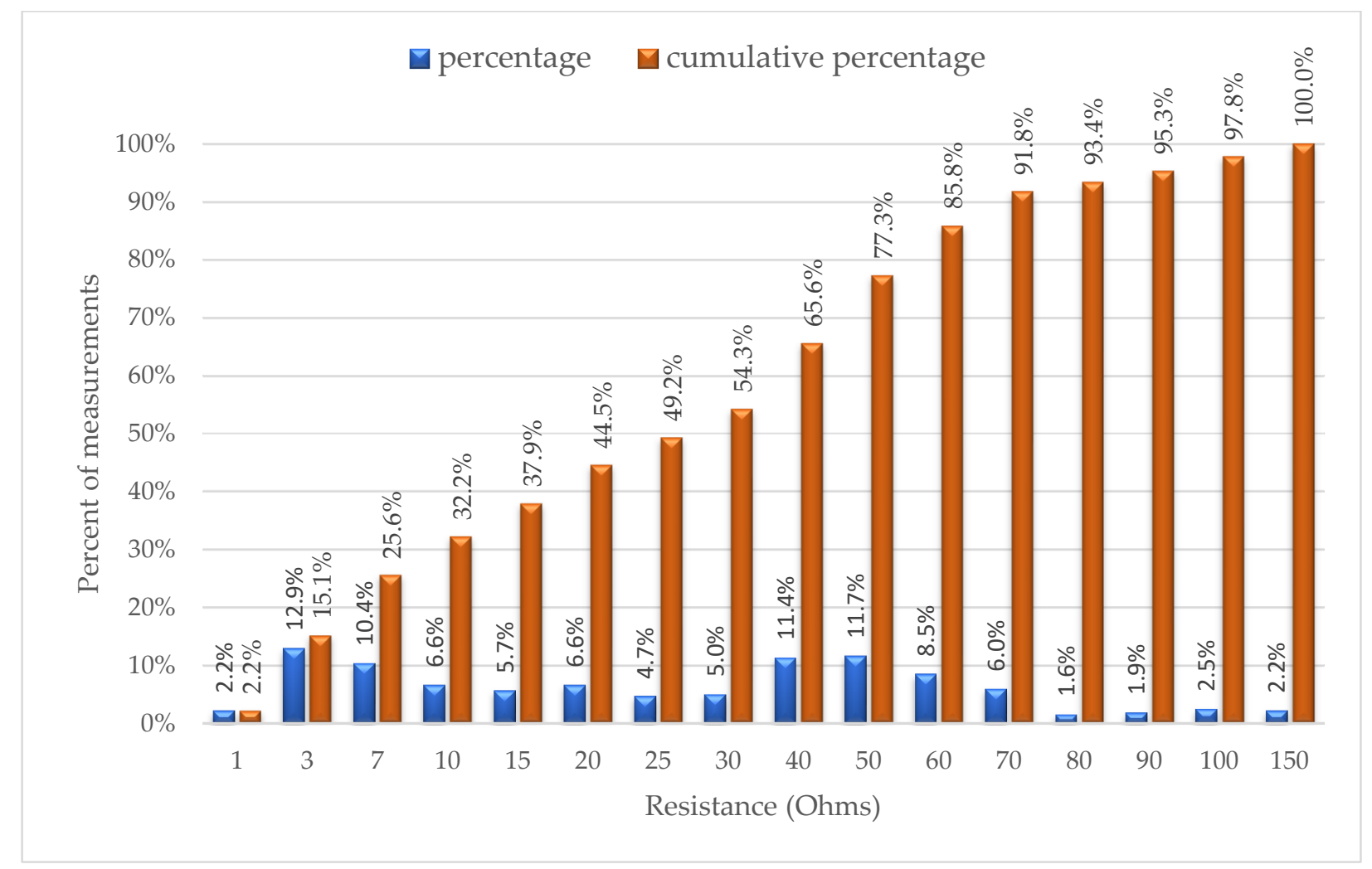

Figure 8. Percentage of wind turbines versus ground resistance value (blue) and probability distribution function (red). 


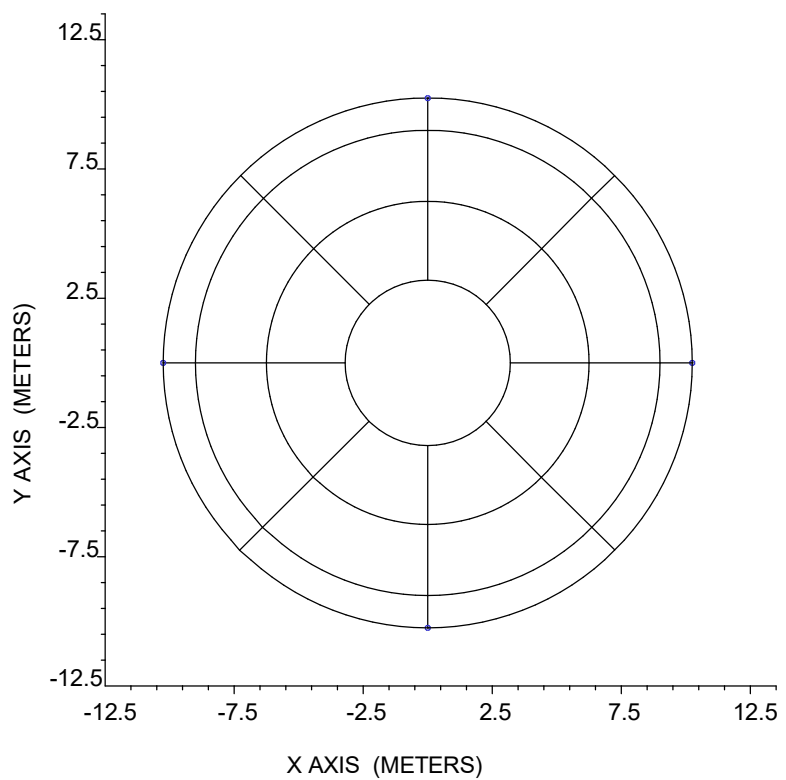

(a)

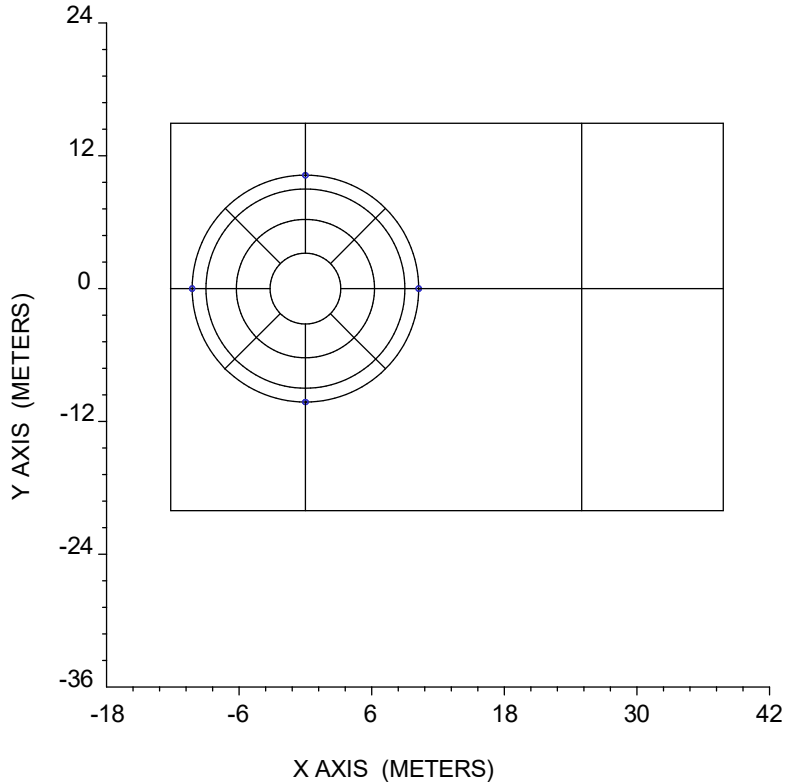

(b)

Figure 9. Top view of a typical wind turbine earthing system: (a) foundation earthing system, (b) enhanced earthing system.

Reliable soil resistivity measurements play an extremely important role in designing the most suitable and advantageous earthing system. It is highlighted that the single-digit value of ground resistance should not be the only criterion while designing a wind turbine earthing system, but the safe operation of the wind turbine, for personnel and equipment, throughout the life of the project. On the other hand, the requirement for a single-digit value of ground resistance according to [36], cannot always be translated directly into practice due to ground structure and morphology, resulting in the limitation of touch and step voltages below the safety limits to be the main objective of the ground study of a wind farm.

\section{Conclusions}

The present work presents the results of a long-term recording and observation of lightning strikes upon the wind turbine generators of ten (10) wind farms distributed throughout the Hellenic territory during the period 2011-2020. The main parameters recorded from the ten stations were the number of lightning flashes per wind farm, the lightning flash polarity and the lightning current amplitude. Thus, the flashes have been categorized to positive and negative ones and the lightning activity at each wind farm has been analyzed separately for positive and negative flashes. More specifically, from the statistical analysis of the 10-year data, the annual number of positive and negative lightning strikes as well as the corresponding monthly average number of strikes per farm have been obtained. Considering these indices, one can obtain a full view of the annual and the total 10-year lightning occurrence at each farm and, hence, at the respective geographic regions of the country. The data processing results show that the western and NW regions experience severe stormy phenomena, rich in lightning discharges even in the summer months, where the summer storms occurring at regions near the sea are very rich of lightning incidences. This claim is also confirmed by the monthly average number during the 10-year observation, as lightning occurrence is noticeably increased in the summer months, specifically, from May to September over the wind parks of the northern and NW Hellenic mainland (WP3, WP4, WP5, and WP10), with the maximum value of CG lightning flashes detected in June.

Furthermore, the negative flash is clearly the dominant type of lightning strikes at all parks according to the 10-year annual mean. The recorded data, however, reveal that the current amplitude of positive lightning flashes obtains higher values than the respective 
ones for negative flashes, a fact that has to be seriously considered during the design stage according to the selected geographic location for the wind farm. This study provides all interested parties with aggregated and very useful data about lightning occurrence and characteristics in Greece in order to make right decisions on the various project stages, such as selection of the wind farm site, proper and in-depth risk assessment, investment in safety measures for personnel and equipment, etc.

The present work provides data for properly designing and modeling grounding systems, which constitute one of the most important parts of electrical installations for the safety of humans and livestock, and equipment integrity as well, playing a major role in the proper operation of facilities. The data for ground resistance values obtained from measurements conducted by the High Voltage Laboratory of NTUA at numerous wind farms around Greece show that only $32 \%$ of the measured wind turbines present ground resistance value lower than $10 \Omega$. However, though the share of wind turbines with ground resistance value around 40 or $50 \Omega$ is quite high, no off-limits step and touch voltages are developed in these cases because of the proper design of the grounding system, ensuring sufficient protection against damage due to lightning flashes that correspond to the LPL for which the wind turbine protection system is designed. Moreover, the measurement data give a view of the soil structure and resistivity per geographic region all over the country, which effect on the configured resistance value of grounding systems in a substantial way. These data, therefore, constitute another useful criterion for the preliminary design of grounding system in respect to the selected site.

Author Contributions: Conceptualization, K.D.D., E.P.N. and I.F.G.; methodology, K.D.D. and E.P.N.; investigation—formal analysis, V.P.A.; writing—original draft preparation, V.P.A.; writing—review and editing, V.P.A., K.D.D., E.P.N. and I.F.G.; supervision, V.P.A. and I.F.G.; project administration, I.F.G. All authors have read and agreed to the published version of the manuscript.

Funding: This research received no external funding.

Institutional Review Board Statement: Not applicable.

Informed Consent Statement: Not applicable.

Conflicts of Interest: The authors declare no conflict of interest.

\section{Appendix A}

Table A1. Percentage of total lightning flashes for positive and negative ones per wind farm.

\begin{tabular}{ccc}
\hline Wind Farm & Positive Flashes & Negative Flashes \\
\hline WP1 & $19.51 \%$ & $80.49 \%$ \\
WP2 & $18.43 \%$ & $81.57 \%$ \\
WP3 & $19.45 \%$ & $80.55 \%$ \\
WP4 & $25.54 \%$ & $74.46 \%$ \\
WP5 & $23.73 \%$ & $76.27 \%$ \\
WP6 & $24.78 \%$ & $75.22 \%$ \\
WP7 & $7.06 \%$ & $92.94 \%$ \\
WP8 & $20.83 \%$ & $79.17 \%$ \\
WP9 & $26.79 \%$ & $73.21 \%$ \\
WP10 & $29.57 \%$ & $70.43 \%$ \\
Total & $22.84 \%$ & $77.16 \%$ \\
\hline
\end{tabular}


Table A2. Lightning strikes in autumn as a percentage of the total strikes per year.

\begin{tabular}{|c|c|c|c|c|c|c|c|c|c|c|}
\hline \multirow{3}{*}{ Year } & \multicolumn{10}{|c|}{ Lightning Strikes Percent } \\
\hline & \multicolumn{7}{|c|}{ Islands and Coastline } & \multicolumn{3}{|c|}{ Mainland } \\
\hline & WP1 & WP2 & WP4 & WP5 & WP6 & WP8 & WP9 & WP3 & WP7 & WP10 \\
\hline 2011 & $66 \%$ & $68 \%$ & $38 \%$ & $59 \%$ & $50 \%$ & $25 \%$ & $0 \%$ & $43 \%$ & $28 \%$ & $7 \%$ \\
\hline 2012 & $60 \%$ & $80 \%$ & $36 \%$ & $43 \%$ & $100 \%$ & $0 \%$ & $0 \%$ & $3 \%$ & $11 \%$ & $5 \%$ \\
\hline 2013 & $78 \%$ & $73 \%$ & $42 \%$ & $55 \%$ & $57 \%$ & $25 \%$ & $25 \%$ & $1 \%$ & $24 \%$ & $15 \%$ \\
\hline 2014 & $53 \%$ & $35 \%$ & $25 \%$ & $14 \%$ & $90 \%$ & $15 \%$ & $51 \%$ & $9 \%$ & $38 \%$ & $7 \%$ \\
\hline 2015 & $54 \%$ & $73 \%$ & $20 \%$ & $12 \%$ & $50 \%$ & $64 \%$ & $25 \%$ & $5 \%$ & $30 \%$ & $7 \%$ \\
\hline 2016 & $53 \%$ & $72 \%$ & $39 \%$ & $29 \%$ & $88 \%$ & $93 \%$ & $100 \%$ & $26 \%$ & $13 \%$ & $9 \%$ \\
\hline 2017 & $49 \%$ & $55 \%$ & $27 \%$ & $39 \%$ & $100 \%$ & $75 \%$ & $100 \%$ & $2 \%$ & $19 \%$ & $31 \%$ \\
\hline 2018 & $20 \%$ & $13 \%$ & $10 \%$ & $2 \%$ & $67 \%$ & $31 \%$ & $40 \%$ & $7 \%$ & $39 \%$ & $6 \%$ \\
\hline 2019 & $62 \%$ & $80 \%$ & $44 \%$ & $51 \%$ & $87 \%$ & $25 \%$ & $33 \%$ & $35 \%$ & $52 \%$ & $5 \%$ \\
\hline 2020 & $40 \%$ & $75 \%$ & $36 \%$ & $37 \%$ & $33 \%$ & $0 \%$ & $10 \%$ & $11 \%$ & $18 \%$ & $14 \%$ \\
\hline $\begin{array}{c}\text { Global } \\
\text { mean }\end{array}$ & $55 \%$ & $67 \%$ & $31 \%$ & $30 \%$ & $76 \%$ & $45 \%$ & $45 \%$ & $18 \%$ & $31 \%$ & $12 \%$ \\
\hline
\end{tabular}

Table A3. Of the recorded positive lightning strikes per wind park.

\begin{tabular}{ccccccccccc}
\hline \multirow{2}{*}{ Month } & \multicolumn{7}{c}{ Average Amplitude (kA) of Positive Lightning Strikes } \\
\cline { 2 - 10 } & WP1 & WP2 & WP3 & WP4 & WP5 & WP6 & WP7 & WP8 & WP9 & WP10 \\
\hline January & 16.24 & 19.37 & 0.57 & 15.37 & 12.29 & 0.00 & 0.00 & 4.10 & 8.74 & 12.77 \\
February & 8.55 & 17.64 & 3.33 & 12.58 & 18.22 & 0.00 & 9.22 & 7.38 & 10.62 & 12.26 \\
March & 4.12 & 2.00 & 0.84 & 8.24 & 3.81 & 0.00 & 0.00 & 0.00 & 0.00 & 15.63 \\
April & 8.88 & 9.87 & 7.59 & 11.95 & 11.12 & 0.00 & 0.00 & 0.00 & 3.22 & 5.29 \\
May & 2.55 & 9.35 & 15.23 & 16.00 & 10.60 & 0.00 & 12.76 & 0.00 & 0.00 & 17.00 \\
June & 4.43 & 3.13 & 11.01 & 9.98 & 8.71 & 3.55 & 9.92 & 3.80 & 1.94 & 10.70 \\
July & 2.77 & 1.81 & 8.88 & 8.10 & 7.06 & 2.71 & 6.45 & 0.00 & 0.00 & 5.73 \\
August & 3.82 & 3.27 & 9.60 & 7.87 & 6.96 & 2.04 & 0.83 & 2.23 & 0.90 & 4.46 \\
September & 10.25 & 7.75 & 9.86 & 13.31 & 9.83 & 4.37 & 6.30 & 1.28 & 0.88 & 3.75 \\
October & 21.57 & 13.84 & 7.29 & 17.27 & 24.31 & 3.38 & 24.54 & 0.62 & 0.00 & 7.83 \\
November & 20.69 & 15.39 & 7.93 & 16.76 & 11.38 & 7.90 & 2.11 & 16.58 & 8.38 & 13.61 \\
December & 11.74 & 17.76 & 3.66 & 10.04 & 8.61 & 3.29 & 0.00 & 9.36 & 1.88 & 10.95 \\
Global mean & 9.63 & 10.10 & 7.15 & 12.29 & 11.08 & 2.27 & 6.01 & 3.78 & 3.05 & 10.00 \\
\hline
\end{tabular}

Table A4. Monthly average amplitude (kA) (observation period 2011-2020) of the recorded negative lightning strikes per wind park.

\begin{tabular}{ccccccccccc}
\hline \multirow{2}{*}{ Month } & \multicolumn{8}{c}{ Average Amplitude (kA) of Negative Lightning Strikes } \\
\cline { 2 - 11 } & WP1 & WP2 & WP3 & WP4 & WP5 & WP6 & WP7 & WP8 & WP9 & WP10 \\
\hline January & 16.74 & 17.26 & 0.00 & 12.00 & 3.97 & 8.35 & 4.99 & 9.60 & 4.86 \\
February & 13.12 & 13.19 & 4.08 & 10.89 & 7.09 & 1.30 & 3.93 & 3.70 & 0.74 & 9.76 \\
March & 17.01 & 10.16 & 10.31 & 12.54 & 10.39 & 0.00 & 5.14 & 0.00 & 1.58 & 7.00 \\
April & 6.53 & 17.56 & 6.41 & 15.33 & 17.63 & 0.00 & 5.62 & 0.00 & 3.24 & 8.63 \\
May & 9.92 & 9.08 & 12.16 & 14.43 & 11.13 & 6.38 & 17.09 & 2.48 & 1.93 & 11.07 \\
June & 7.98 & 6.32 & 12.75 & 12.40 & 13.54 & 2.78 & 20.47 & 9.60 & 3.42 & 12.12 \\
July & 5.41 & 2.80 & 12.12 & 11.90 & 11.26 & 2.13 & 12.20 & 1.50 & 1.57 & 10.05 \\
August & 8.45 & 3.99 & 12.18 & 13.34 & 10.56 & 0.00 & 11.33 & 1.86 & 3.79 & 9.96 \\
September & 12.89 & 14.73 & 9.79 & 16.29 & 13.03 & 7.26 & 11.09 & 7.47 & 1.25 & 11.51 \\
October & 17.85 & 12.96 & 6.27 & 13.77 & 14.25 & 10.59 & 15.58 & 4.69 & 6.98 & 13.43 \\
November & 13.54 & 13.04 & 5.21 & 13.45 & 6.93 & 16.22 & 7.24 & 10.95 & 7.89 & 6.95 \\
December & 11.18 & 16.42 & 2.72 & 12.94 & 5.53 & 0.00 & 5.55 & 5.14 & 3.03 & 4.91 \\
Global & 11.72 & 11.46 & 7.83 & 13.28 & 10.44 & 4.58 & 10.02 & 4.75 & 3.36 \\
mean & & & & & & & & 9.30 & \\
\hline
\end{tabular}




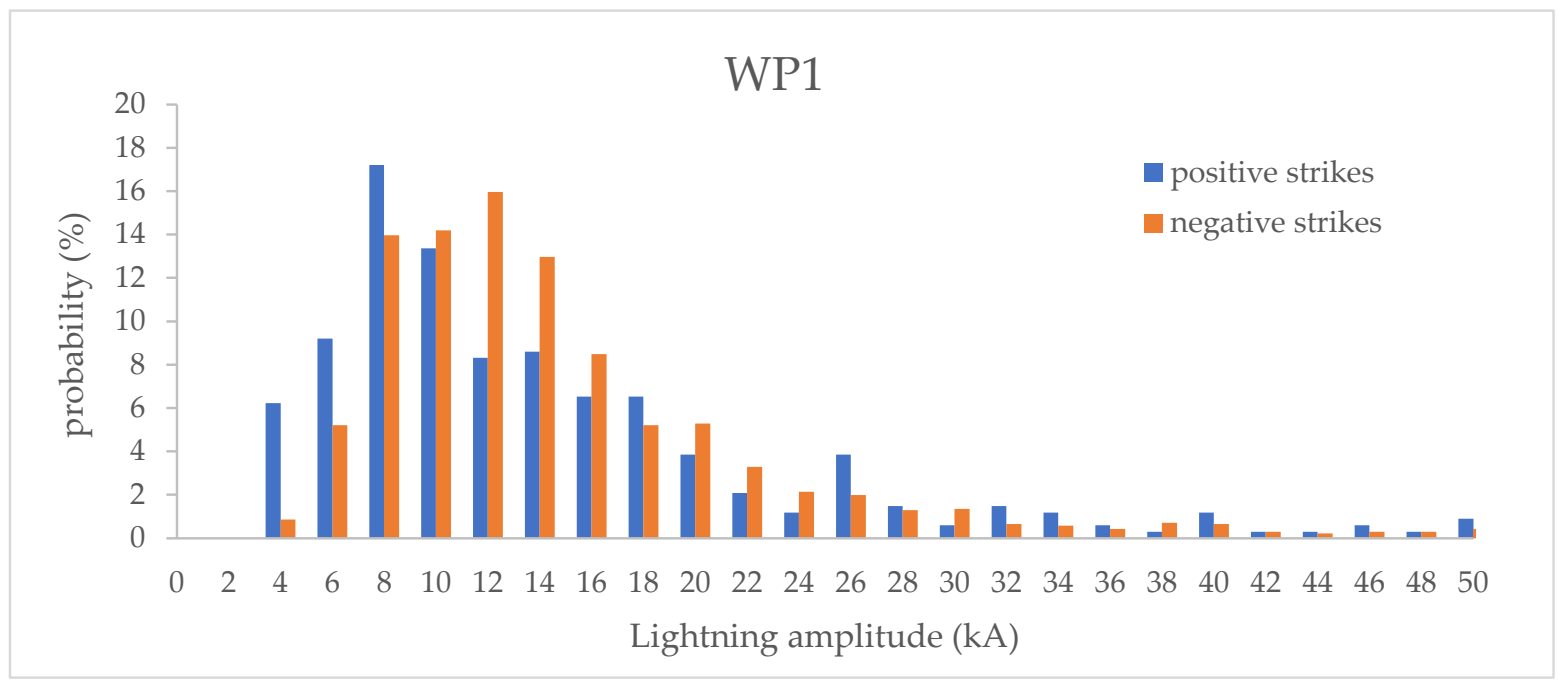

Figure A1. Lightning current amplitude probability distributions for positive and negative strikes extracted from the recorded incidents throughout the period 2011-2020 for WP1.

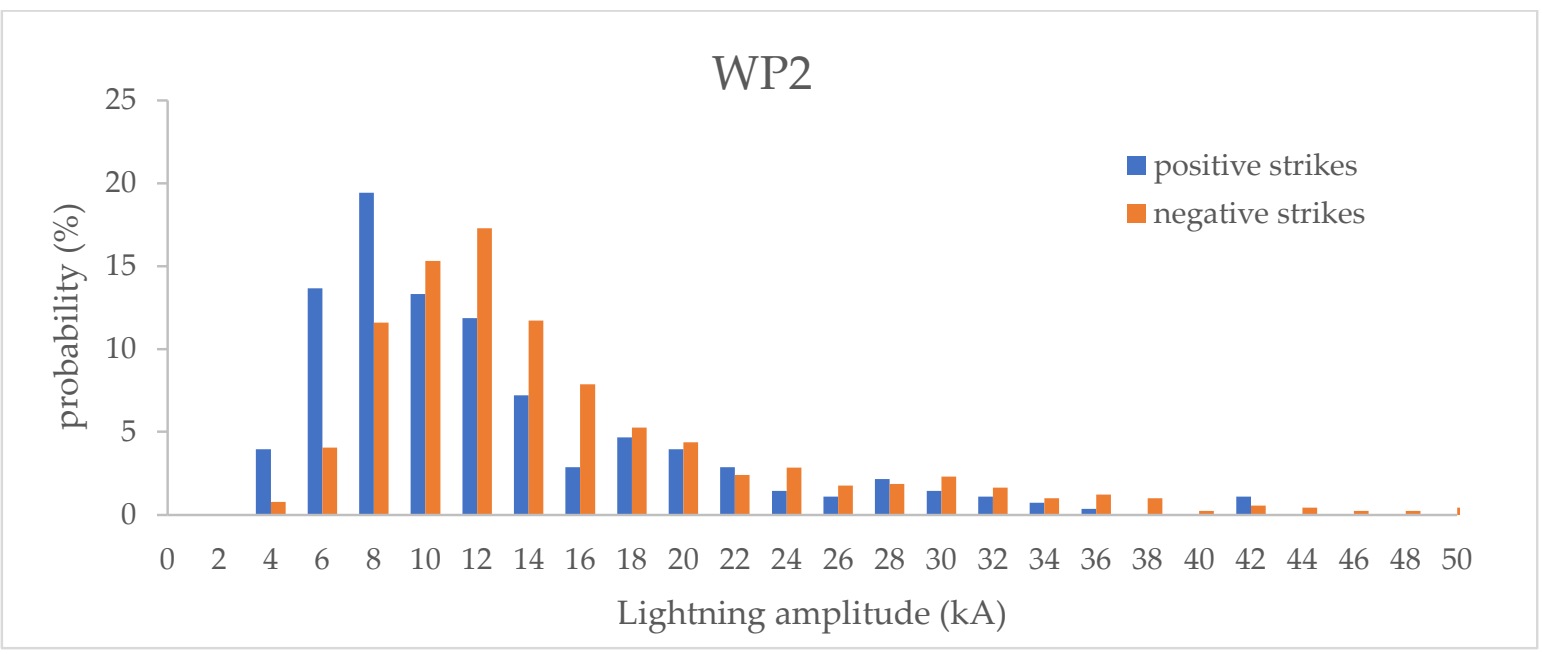

Figure A2. Lightning current amplitude probability distributions for positive and negative strikes extracted from the recorded incidents throughout the period 2011-2020 for WP2.

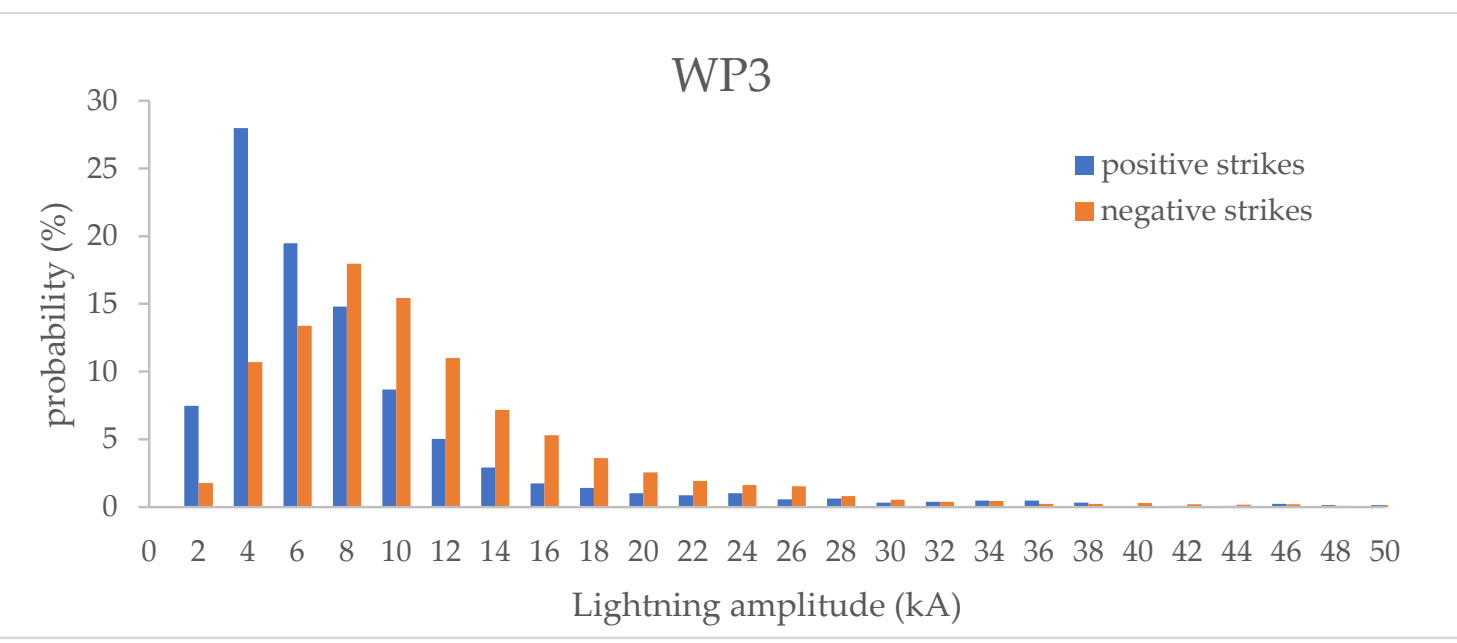

Figure A3. Lightning current amplitude probability distributions for positive and negative strikes extracted from the recorded incidents throughout the period 2011-2020 for WP3. 


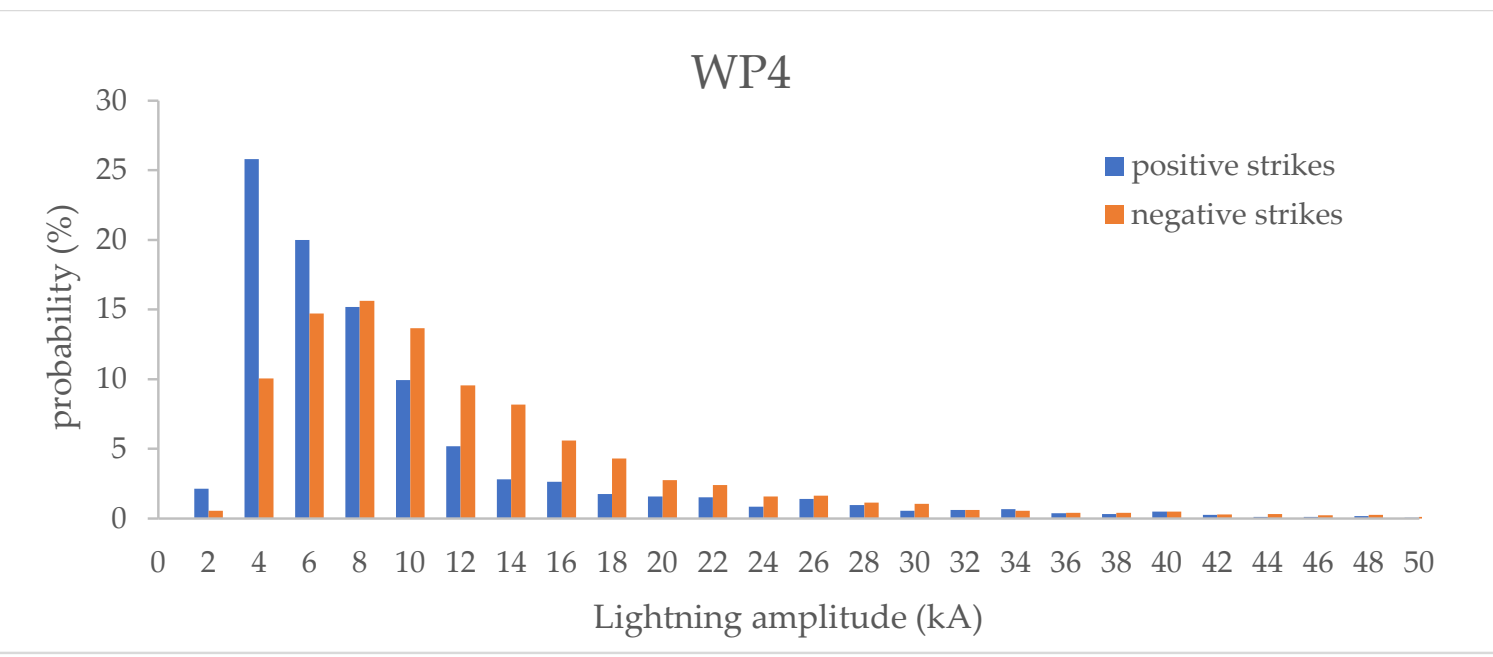

Figure A4. Lightning current amplitude probability distributions for positive and negative strikes extracted from the recorded incidents throughout the period 2011-2020 for WP4.

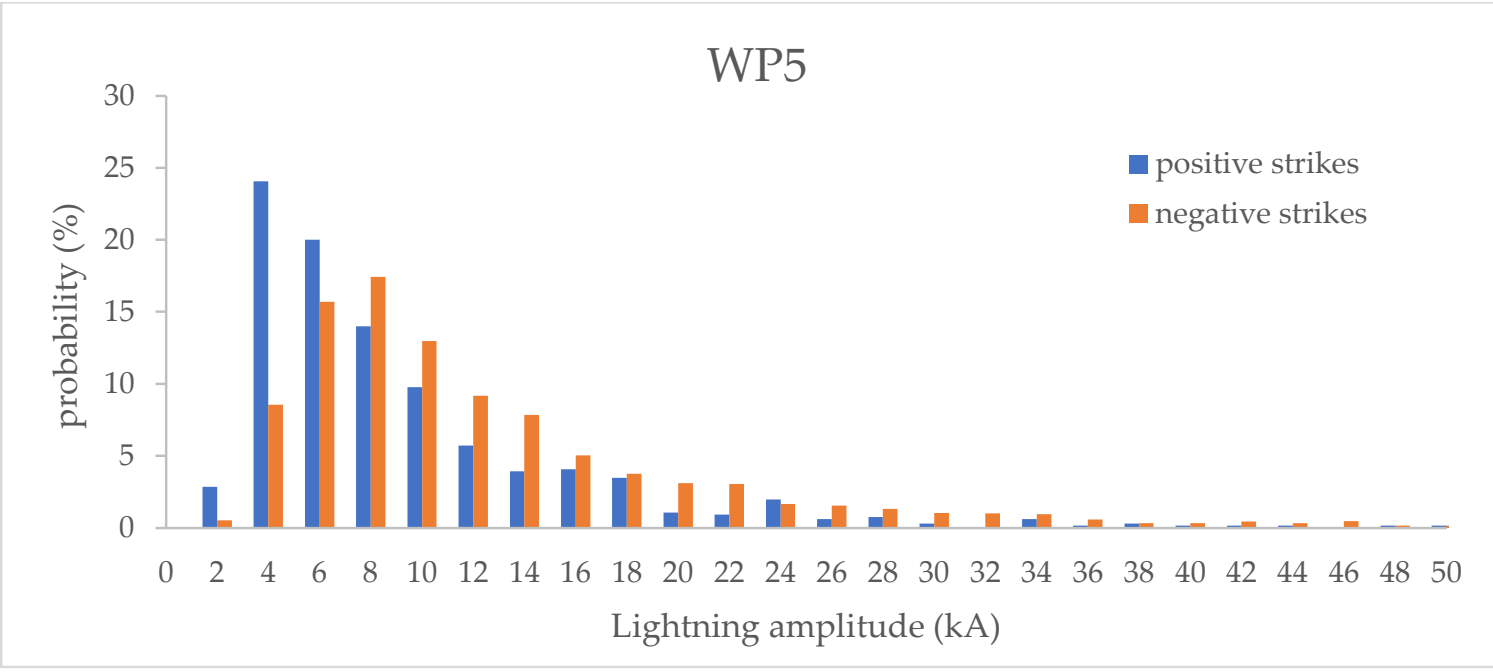

Figure A5. Lightning current amplitude probability distributions for positive and negative strikes extracted from the recorded incidents throughout the period 2011-2020 for WP5.

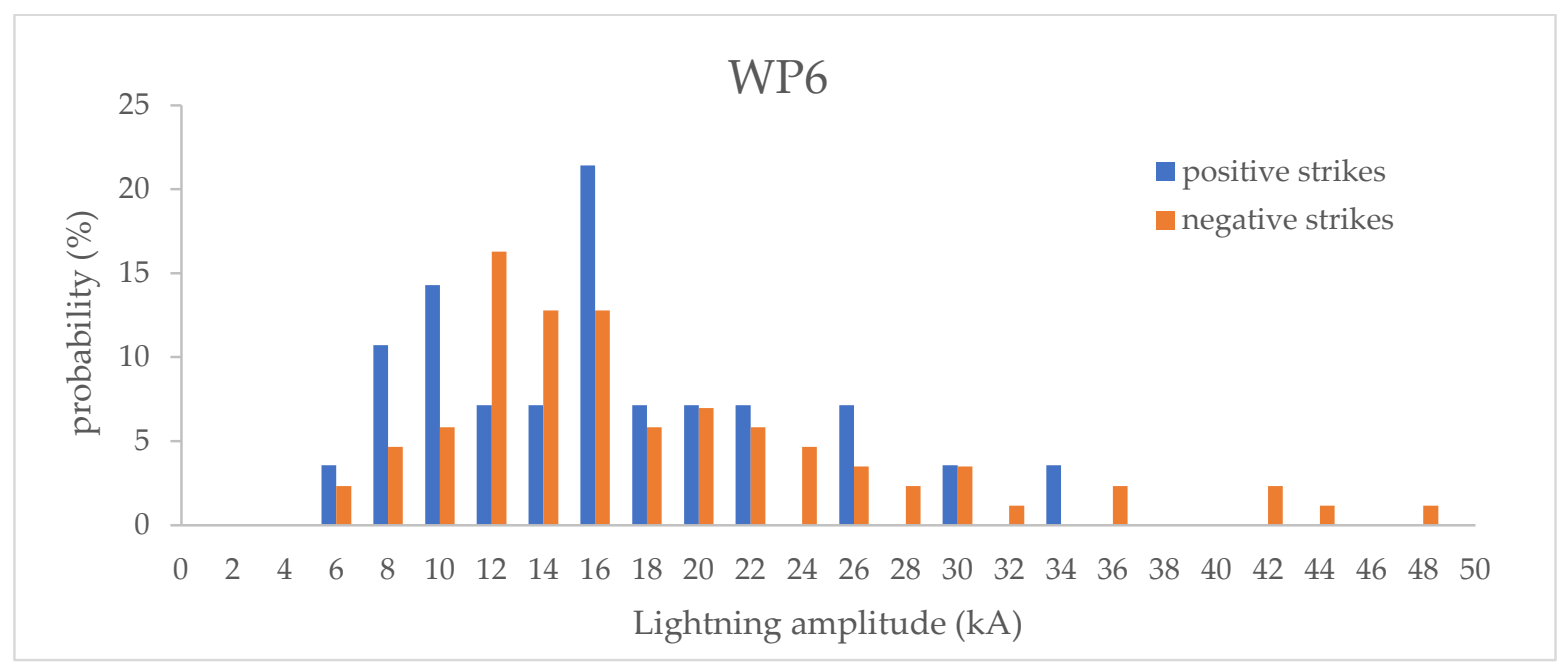

Figure A6. Lightning current amplitude probability distributions for positive and negative strikes extracted from the recorded incidents throughout the period 2011-2020 for WP6. 


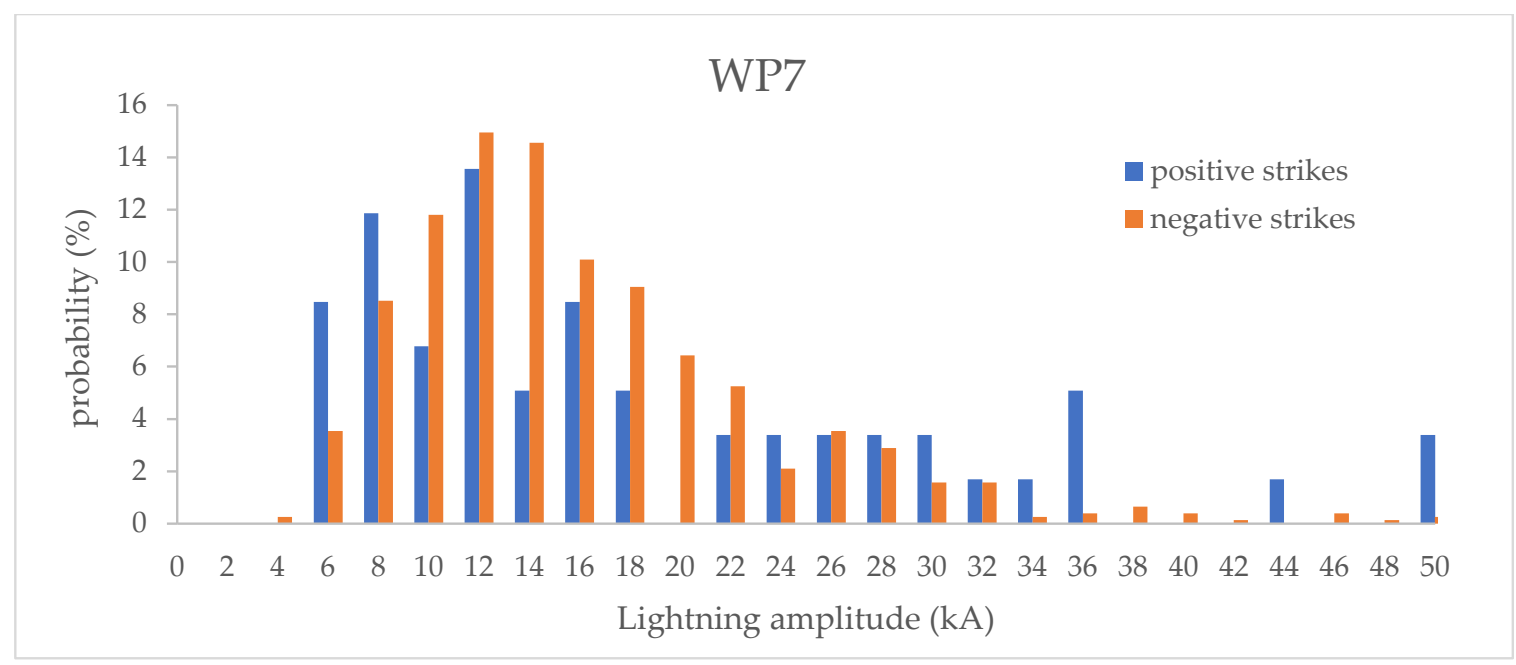

Figure A7. Lightning current amplitude probability distributions for positive and negative strikes extracted from the recorded incidents throughout the period 2011-2020 for WP7.

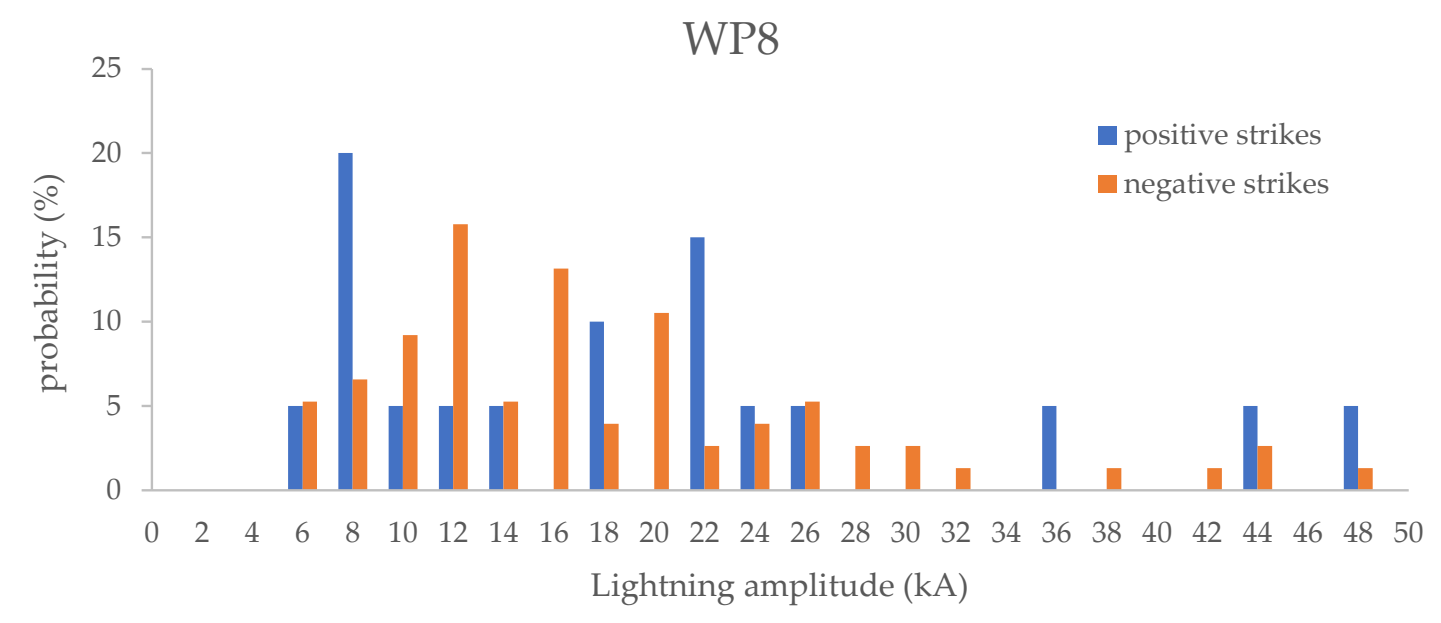

Figure A8. Lightning current amplitude probability distributions for positive and negative strikes extracted from the recorded incidents throughout the period 2011-2020 for WP8.

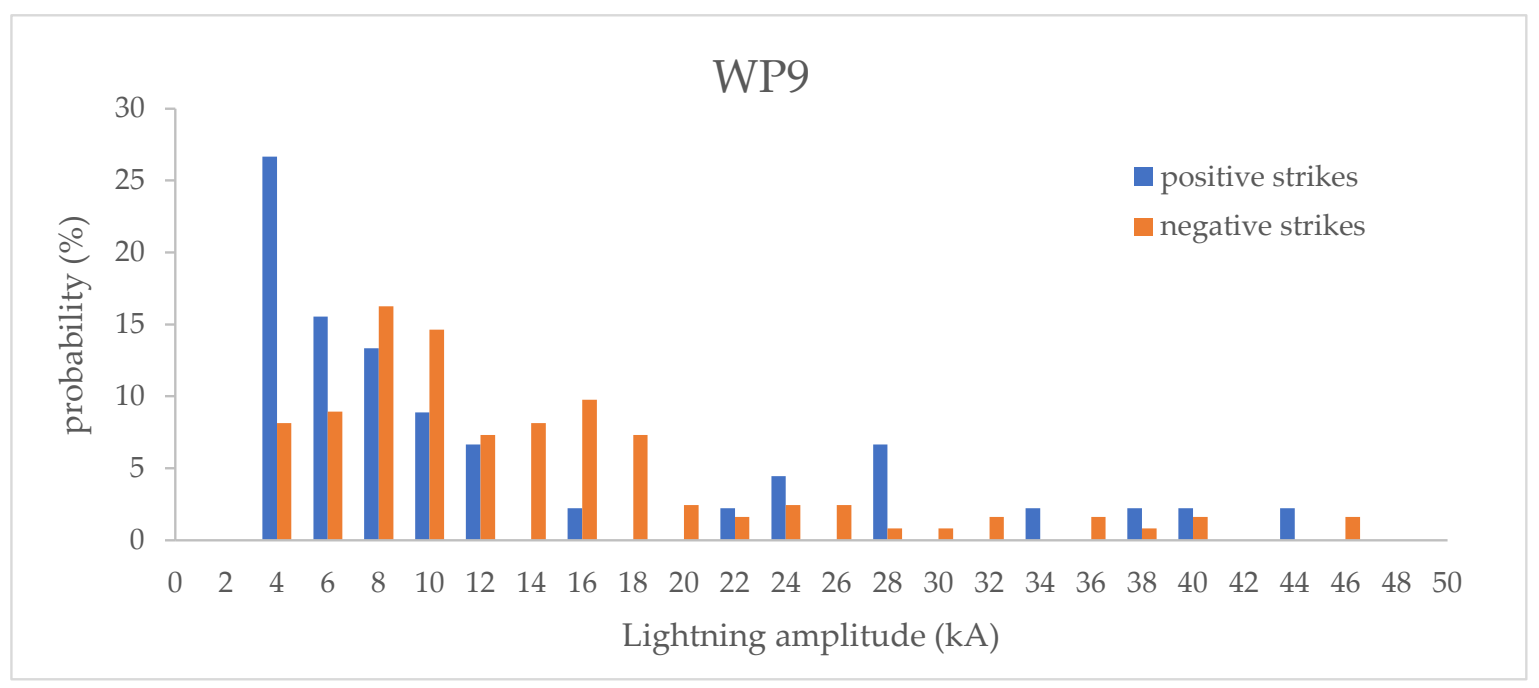

Figure A9. Lightning current amplitude probability distributions for positive and negative strikes extracted from the recorded incidents throughout the period 2011-2020 for WP9. 


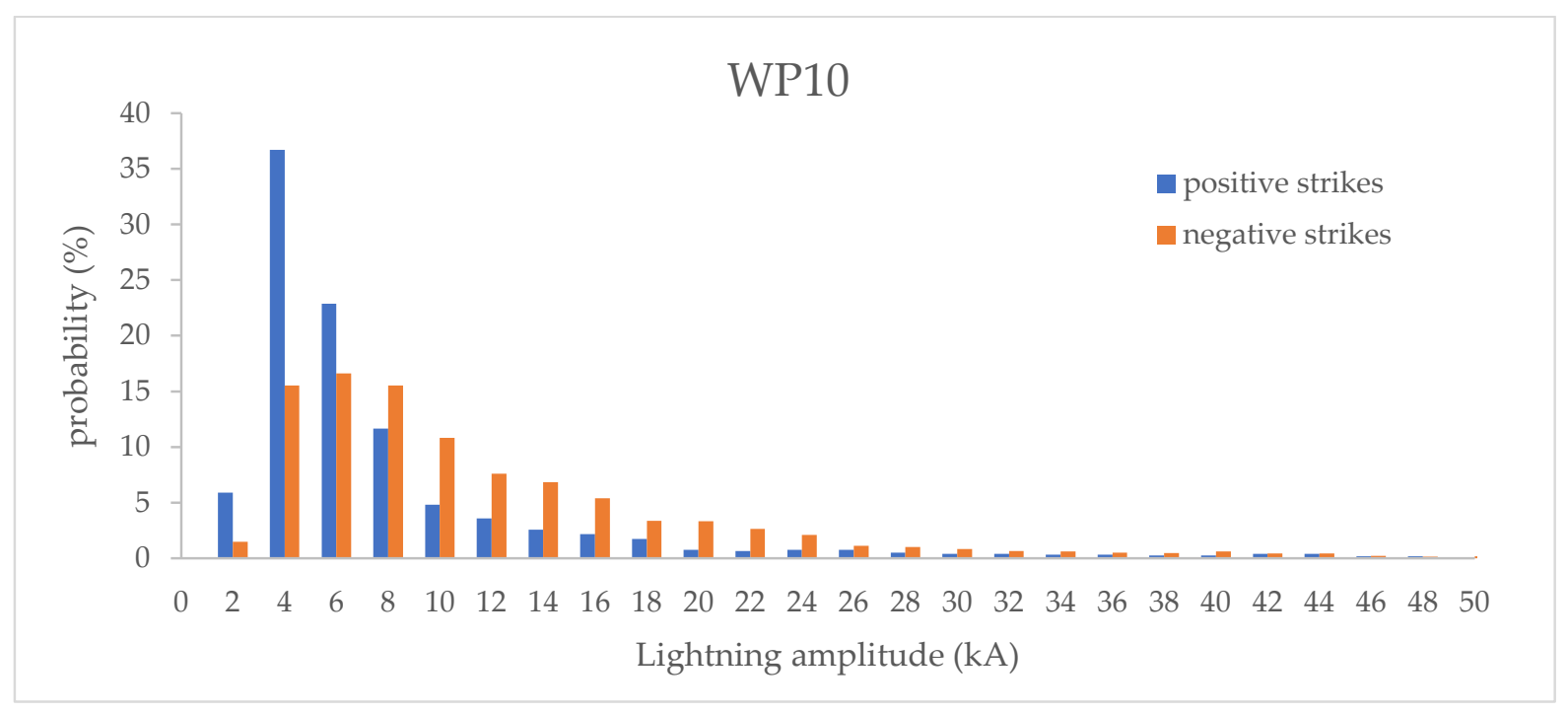

Figure A10. Lightning current amplitude probability distributions for positive and negative strikes extracted from the recorded incidents throughout the period 2011-2020 for WP10.

\section{References}

1. CIGRE TB 549-2013 Lightning Parameters for Engineering Applications. 2013. Available online: https: / / ieeexplore.ieee.org/ document/6729246 (accessed on 24 September 2021).

2. IEC 62305-1:2010 Protection against Lightning-Part 1: General Principles. 2010. Available online: https://webstore.iec.ch/ publication/ 6793 (accessed on 24 September 2021).

3. Heidler, F.; Zischank, W.; Flisowski, Z.; Bouquegneau, C.; Mazzetti, C. Parameters of lightning current given in IEC 62350Background, experience and outlook. In Proceedings of the 29th International Conference on Lightning Protection (ICLP), Uppsala, Sweden, 23-26 June 2008.

4. IEC 62305-2:2010-12 Protection against Lightning-Part 2: Risk Management. 2010. Available online: https://webstore.iec.ch/ publication/6794 (accessed on 24 September 2021).

5. Berger, K. Novel observations on lightning discharges: Results of research on Mount San Salvatore. J. Frankl. Inst. 1967, 283, 478-525. [CrossRef]

6. $\quad$ Berger, K.; Anderson, R.B.; Kroninger, H. Parameters of lightning flashes. Electra 1975, 80, $23-37$.

7. Garbagnati, E.; LoPiparo, G.B. Lightning parameters-Results of 10 years investigation in Italy. In Proceedings of the International Conference on Lightning and Static Electricity (ICOLSE), Oxford, UK, 23-25 March 1982.

8. Geldenhuys, H.; Eriksson, A.; Bouon, A. Fifteen years' data of lightning current measurement on a $60 \mathrm{~m}$ mast. In Proceedings of the 19th International Conference on Lightning Protection (ICLP), Graz, Austria, 25-29 April 1988.

9. Goto, Y.; Narita, K.; Komuro, H.; Honma, N. Current waveform measurement of winter lightning struck an isolated tower. In Proceedings of the 20th International Conference on Lightning Protection (ICLP), Interlaken, Switzerland, 24-28 September 1990.

10. Fuchs, F.; Landers, E.U.; Schmid, R.; Wiesinger, J. Lightning current and magnetic field parameters caused by lightning strikes to tall structures relating to interference of electronic systems. IEEE Trans. Electromagn. Compat. 1998, 40, 444-451. [CrossRef]

11. Diendorfer, G.; Mair, M.; Schulz, W.; Hadrian, W. Lightning current measurements in Austria-Experimental setup and first results. In Proceedings of the 25th International Conference on Lightning Protection (ICLP), Rhodes, Greece, 18-22 September 2000.

12. Visacro, S.; Soares, A., Jr.; Schroeder, M.A.O.; Cherchiglia, L.C.L.; Sousa, V.J. Statistical analysis of lightning current parameters: Measurements at Morro do Cachimbo Station. J. Geophys. Res. 2004, 109. [CrossRef]

13. Takami, J.; Okabe, S. Observational results of lightning current on transmission towers. IEEE Trans. Power Deliv. 2007, 22, 547-556. [CrossRef]

14. Diendorfer, G.; Pichler, H.; Mair, M. Some parameters of negative upward-initiated lightning to the Gaisberg tower (2000-2007). IEEE Trans. Electromagn. Compat. 2009, 51, 443-452. [CrossRef]

15. Miki, T.; Shindo, T.; Asakawa, A.; Motoyama, H.; Ishii, M.; Suzuhigashi, Y.; Fukuda, K.; Chihara, M. Measurement of lightning currents at TOKYO SKYTREE and observation of electromagnetic radiation caused by strikes to the tower. In Proceedings of the 2012 International Conference on Lightning Protection (ICLP), Vienna, Austria, 2-7 September 2012.

16. Ohki, Y. Observation of lightning strikes at Tokyo skytree [News from Japan]. IEEE Electr. Insul. Mag. 2016, 32, 57-59. [CrossRef]

17. Miki, T.; Saito, M.; Shindo, T.; Ishii, M. Current observation results of downward negative flashes at Tokyo Skytree from 2012 to 2018. IEEE Trans. Electromagn. Compat. 2019, 61, 663-673. [CrossRef] 
18. Qiu, Z.; Gao, H.; Yang, Y. Lightning parameters measurement systems and instrumentation on meteorological gradient observation tower in Shenzhen China. In Proceedings of the 2015 International Symposium on Lightning Protection (XIII SIPDA), Balneário Camboriú, Brazil, 28 September-2 October 2015.

19. Jun, Y.; Li, G.; Liu, H.; Yang, G.; Ling, G. Design of a flexible Rogowski coil with active integrator applied in lightning current collection. In Proceedings of the 33rd International Conference on Lightning Protection (ICLP), Estoril, Portugal, 25-30 September 2016.

20. Heidler, F.; Zischank, W.; Wiesinger, J. Statistics of lightning current parameters and related nearby magnetic fields measured at the Peissenberg tower. In Proceedings of the 25th International Conference on Lightning Protection (ICLP), Rhodes, Greece, 18-22 September 2000.

21. Schoene, J.; Uman, M.A.; Rakov, V.A.; Rambo, K.J.; Jerauld, J.; Mata, C.T.; Mata, A.G.; Jordan, D.M.; Schnetzer, G.H. Characterization of return-stroke currents in rocket-triggered lightning. J. Geophys. Res. 2009, 114. [CrossRef]

22. Depass, P. Statistics on artificially triggered lightning. J. Geophys. Res. 1994, 99, 186515-186522. [CrossRef]

23. Miyake, K.; Horii, K. Five years' experiences on artificially triggered lightning in Japan. In Proceedings of the 7th IEE-Conference Gas Discharges and their Applications, London, UK, 31 August-3 September 1982.

24. Nakamura, K.; Horii, K.; Sakurano, H.; Sumi, S.-I.; Yoda, M.; Kawasaki, Z.-I. Wakamatsu, M Lightning discharge parameters by rocket triggered lightning to transmission line in winter. In Proceedings of the 10th International Symposium on High Voltage Engineering (ISH), Montreal, QC, Canada, 25-29 August 1997.

25. Yasui, S.; Takuwa, T.; Morishima, D.; Sumi, S.; Morimoto, T.; Horii, K. Observation of lightning current in the soil by rockettriggered lightning. In Proceedings of the 33rd International Conference on Lightning Protection (ICLP), Estoril, Portugal, 25-30 September 2016.

26. Liu, X.; Zhang, Y. Review of artificially triggered lightning study in China. IEEJ Trans. Power Energy 1998, 118, 170-175. [CrossRef]

27. Qie, X.; Jiang, R.; Sun, Z.; Liu, M.; Wang, Z.; Lu, G.; Zhang, H. High resolution observation on rocket-triggered lightning. In Proceedings of the 2014 International Conference on Lightning Protection (ICLP), Shanghai, China, 11-18 October 2014.

28. Ma, Z.; Jiang, R.; Sun, Z.; Zhang, H.; Qie, X.; Xing, H.; Liu, M.; Li, X.; Pu, Y.; Dong, Z. Characteristics of impulsive currents superimposing on continuous/continuing current of rocket-triggered lightning. IEEE Trans. Electromagn. Compat. 2020, 62, 1200-1208. [CrossRef]

29. Bejleri, M.; Rakov, V.A.; Uman, M.A.; Rambo, K.J.; Mata, C.T.; Fernandez, M.I. Triggered lightning testing of an airport runway lightning system. IEEE Trans. Electromagn. Compat. 2004, 46, 96-101. [CrossRef]

30. Rakov, V.A.; Uman, M.A.; Rambo, K.J. A review of ten years of triggered-lightning experiments in Camp Blanding, Florida. J. Atmos. Res. 2005, 76, 503-517. [CrossRef]

31. Mallick, S.; Rakov, V.A. Characterization of far electric field waveforms produced by rocket-triggered lightning. In Proceedings of the 2014 International Conference on Lightning Protection (ICLP), Shanghai, China, 11-18 October 2014.

32. Cummins, K.L.; Murphy, M.J. An Overview of Lightning Locating Systems: History, Techniques, and Data Uses, With an In-Depth Look at the U.S. NLDN. IEEE Trans. Electromagn. Compat. 2009, 51, 499-518. [CrossRef]

33. Fata, A.L.; Tosi, I.; Brignone, M.; Procopio, R.; Delfino, F. A review of lightning location systems: Part I—Methodologies and techniques. In Proceedings of the 2020 IEEE International Conference on Environment and Electrical Engineering and 2020 IEEE Industrial and Commercial Power Systems Europe (EEEIC/I\&CPS Europe), Madrid, Spain, 9-12 June 2020.

34. Matsangouras, I.T.; Nastos, P.T.; Kapsomenakis, J. Cloud-to-ground lightning activity over Greece: Spatio-temporal analysis and impacts. Atmos. Res. 2016, 169, 485-496. [CrossRef]

35. Galanaki, E.; Kotroni, V.; Lagouvardos, K.; Argiriou, A. A ten-year analysis of cloud-to-ground lightning activity over the Eastern Mediterranean region. Atmos. Res. 2015, 166, 213-222. [CrossRef]

36. Wind Turbines Part 24: Lightning Protection; IEC 61400-24 ed. 1.0; International Electrotechnology Commission: London, UK, 2010.

37. Peppas, G.D.; Bekas, K.I.; Naxakis, I.; Pyrgioti, E.C.; Charalampakos, V.P. Analysis of lightning impacts in Greece. In Proceedings of the 2012 International Conference on Lightning Protection (ICLP), Vienna, Austria, 2-7 September 2012. [CrossRef]

38. IEEE Guide for Safety in AC Substation Grounding, IEEE Std. 80. 2013. Available online: https://ieeexplore.ieee.org/document/ 7109078 (accessed on 24 September 2021).

39. IEEE Guide for Measuring Earth Resistivity, Ground Impedance, and Earth Surface Potentials of a Grounding System, IEEE Std. 81. 2012. Available online: https:/ / ieeexplore.ieee.org/document/ 6392181 (accessed on 24 September 2021).

40. IEEE Guide for Measurement of Impedance and Safety Characteristics of Large, Extended or Interconnected Grounding Systems, IEEE Std. 81.2. 1991. Available online: https:/ / ieeexplore.ieee.org/document/182805 (accessed on 24 September 2021).

41. IEC 61400-24:2019 Wind energy generation systems-Part 24: Lightning Protection. 2019. Available online: https://webstore.iec. ch/publication/32050 (accessed on 24 September 2021). 